NBER WORKING PAPER SERIES

\title{
PROPAGATION AND AMPLIFICATION OF LOCAL PRODUCTIVITY SPILLOVERS
}

\author{
Xavier Giroud \\ Simone Lenzu \\ Quinn Maingi \\ Holger Mueller \\ Working Paper 29084 \\ http://www.nber.org/papers/w29084 \\ NATIONAL BUREAU OF ECONOMIC RESEARCH \\ 1050 Massachusetts Avenue \\ Cambridge, MA 02138 \\ July 2021
}

We thank Costas Arkolakis, Lorenzo Caliendo, Xavier Gabaix, Cecile Gaubert, Elisa Giannone, Matthias Kehrig, Esteban Rossi-Hansberg, Philipp Schnabl, Pete Schott, Amit Seru, Andrei Shleifer, Johannes Stroebel, Amir Sufi, Sharon Traiberman, and various seminar audiences for helpful comments and suggestions. We are grateful to Jun Wong for excellent research assistance. Any views expressed are those of the authors and not those of the U.S. Census Bureau. The Census Bureau's Disclosure Review Board and Disclosure Avoidance Officers have reviewed this information product for unauthorized disclosure of confidential information and have approved the disclosure avoidance practices applied to this release. This research was performed at a Federal Statistical Research Data Center under FSRDC Project Number 1908 (CBDRB-FY21P1908-R9062). The views expressed herein are those of the authors and do not necessarily reflect the views of the National Bureau of Economic Research.

NBER working papers are circulated for discussion and comment purposes. They have not been peer-reviewed or been subject to the review by the NBER Board of Directors that accompanies official NBER publications.

(C) 2021 by Xavier Giroud, Simone Lenzu, Quinn Maingi, and Holger Mueller. All rights reserved. Short sections of text, not to exceed two paragraphs, may be quoted without explicit permission provided that full credit, including ()$^{\text {notice, }}$ is given to the source. 
Propagation and Amplification of Local Productivity Spillovers

Xavier Giroud, Simone Lenzu, Quinn Maingi, and Holger Mueller

NBER Working Paper No. 29084

July 2021

JEL No. C51,C68,E23,E24,L23,O4,R12,R13,R3

\begin{abstract}
$\underline{\text { ABSTRACT }}$ economy.

Xavier Giroud

Columbia Business School

Finance Division

3022 Broadway, Uris Hall 806

New York, NY 10027

and NBER

xavier.giroud@gsb.columbia.edu

Simone Lenzu

Stern School of Business

New York University

44 West Fourth Street

Suite 9-190

New York, NY 10012

slenzu@stern.nyu.edu

\author{
Quinn Maingi \\ Stern School of Business \\ New York University \\ 44 West Fourth Street Suite \\ 9-190 \\ New York, NY 10012 \\ rmaingi@stern.nyu.edu \\ Holger Mueller \\ Stern School of Business \\ New York University \\ 44 West Fourth Street Suite \\ 9-190 \\ New York, NY 10012-1126 \\ and NBER \\ hmueller@stern.nyu.edu
}

This paper shows that local productivity spillovers propagate throughout the economy through the plant-level networks of multi-region firms. Using confidential Census plant-level data, we show that large manufacturing plant openings not only raise the productivity of local plants but also of distant plants hundreds of miles away, which belong to multi-region firms that are exposed to the local productivity spillover through one of their plants. To quantify the significance of plant-level networks for the propagation and amplification of local productivity shocks, we develop and estimate a quantitative spatial model in which plants of multi-region firms are linked through shared knowledge. Our model features heterogeneous regions, which interact through goods trade and labor markets, as well as within-location, across-plant heterogeneity in productivity, wages, and employment. Counterfactual exercises show that while knowledge sharing through plant-level networks amplifies the aggregate effects of local productivity shocks, it widens economic disparities between individual workers and regions in the 


\section{Introduction}

Local governments spend billions of dollars in subsidies every year for companies to locate within their jurisdictions (Story, 2012; Bartik, 2020). From an efficiency standpoint, a common rationale for such place-based incentives is the existence of Marshallian agglomeration economies-spillovers to the local economy in the form of input sharing, labor market pooling, and knowledge externalities-that raise the productivity of local workers and businesses (Moretti, 2010; Kline and Moretti, 2014a; Neumark and Simpson, 2015). In this paper, we provide both reduced-form and model-based evidence that these local productivity spillovers propagate throughout the economy through the plant-level networks of multi-region firms.

Identifying local productivity spillovers is difficult. In our reduced-form analysis, we build on the natural experiments in Greenstone, Hornbeck, and Moretti (2010), who study the effects of large plant openings ("Million Dollar Plants," or MDPs) on the productivity of incumbent plants. In their setting, plants in one or more runner-up counties, which narrowly lost the competition, provide a counterfactual for incumbent plants in the "winner" county, where the MDP ultimately located. Using confidential plant-level data from the Census Bureau, we show that the MDP openings raise the productivity of incumbent plants by $4 \%$. This ("local") productivity spillover is strong within a 50 mile radius around the MDP, weaker within a 100 mile radius, and insignificant beyond. Hence, consistent with a large empirical literature, we find that productivity spillovers between (plants of) different firms decay rapidly with geographical distance. ${ }^{1}$

A different picture emerges when we examine how productivity spillovers spread within firm boundaries. We consider large multi-plant, multi-region firms which are exposed to the MDP openings, and thus to the local productivity spillover, by having a plant in the winner county. We find that, in response to the MDP openings, these firms' plants outside the winner county ("treated plants") experience productivity gains of $1.8 \%$, along with employment gains of $1.6 \%$. To identify the ("global") productivity spillover on plants outside the winner county, we compare plants in the same county, industry, and year that belong to firms which either own plants in the winner county (treatment) or the runner-up counties (control). This specification accounts for the possibility of correlated shocks between the county of the treated plant and the winner county, thus addressing potential concerns that the productivity gains at treated plants may be due to common regional shocks rather than internal spillovers within the firm's boundaries.

\footnotetext{
${ }^{1}$ Rosenthal and Strange $(2004,2020)$ and Combes and Gobillon (2015) review the empirical literature on agglomeration economies. Most empirical studies find that these economies are highy localized.
} 
What explains the global productivity spillover? While the local productivity gains may be due to either labor market pooling or knowledge spillovers, it is unlikely that a thicker labor market in the winner county would affect the productivity of treated plants hundreds of miles away. Knowledge, on the other hand, can be used in local and distant plants alike. Indeed, once it spills over to the firm's local plant, it can be freely shared with other plants inside the firm's boundaries (Markusen, 1984). To explore this issue, we examine if the global productivity spillover becomes weaker as we increase the distance to the MDP. We find that the estimates remain virtually unchanged if we exclude all plants within a 500 mile radius, or within the same state or Census division as the MDP. Hence, unlike the local productivity spillover, which takes place across plants of different firms, the global productivity spillover, which takes place across different plants of the same firm, does not decay with geographical distance. Further, and also consistent with knowledge sharing, we find that the global productivity spillover is much stronger if the distant plant and either the MDP or the firm's plant in the winner county are in the same industry or in (knowledge-based) industries characterized by mutual R\&D flows or patent citations.

In a recent survey article, Rosenthal and Strange (2020) write:

"Implicit in the idea that spatial concentration increases productivity is another idea: the degree of proximity matters. Agglomeration economies must decay with distance. How close, then, do firms and workers need to be to each other to benefit from agglomeration economies? Or more colloquially, how close is close?” (p. 27).

Our paper provides a nuanced answer. On the one hand, firms must have a nearby plant to benefit from knowledge spillovers. As we show, the local agglomeration economy is strongly significant only within a 50 mile radius around the MDP. On the other hand, not all of a firm's plants need to be located nearby. In fact, it may suffice if only one of the firm's plants is located in close proximity to the MDP. Once the knowledge spills over to that plant, it can be passed on to other plants inside the firm's boundaries, increasing the productivity of distant plants hundreds of miles away.

To quantify the significance of knowledge sharing through plant-level networks, we develop and estimate a quantitative spatial model with goods trade, labor mobility, plant-level networks, and a rich and realistic geography. While we build on the theoretical framework developed by Allen and Arkolakis (2014), Ahlfeldt et al. (2015), Redding (2016), and Monte, Redding, and Rossi-Hansberg (2018), we depart from the canonical model in a number of significant ways. ${ }^{2}$ Our model features finitely many firms, some of which

\footnotetext{
${ }^{2}$ Redding and Rossi-Hansberg (2017) provide a comprehensive taxonomy of the modeling assumptions and
} 
have multiple plants in different regions. Plants of the same firm, across regions, are linked through shared knowledge, as in Markusen (1984). Specifically, we assume that plant-level productivity depends on local knowledge and knowledge in the other regions in which the firm operates. This generates heterogeneity in plant-level productivity within a given location and provides a direct mechanism through which productivity shocks in one location may propagate to other locations. ${ }^{3}$

Another point of departure from the canonical model is our focus on within-location labor markets. Specifically, we assume workers have idiosyncratic preferences over both locations and plants within a location. In conjunction with heterogeneity in plant-level productivity, this implies plants within a given location pay different wages, departing from the standard assumption of each location having a single wage. Similar to McFadden (1978), we express workers' location choice problem as a nested choice between different locations and then, within locations, between different plants. This decomposition results in analytically separable within- and across-location problems, which greatly simplifies the computational and analytical characterization of the model's solution. Given parameter values and fundamentals, the model has a unique equilibrium. Moreover, given parameter values and observed data, there exist unique values of the unobserved fundamentals that rationalize the data as an equilibrium of the model.

The typical economic geography model focuses on regional outcomes; parameters can thus often be identified using regional aggregates. By contrast, our model features within-region, across-plant heterogeneity. Hence, plant-level micro moments are needed to identify the parameters. To this end, we use an indirect inference approach and target as moments reduced-form estimates-semi-elasticities of plant-level employment, wages, and productivity to the MDP openings-that are informative about plant-level outcomes. To obtain model-based estimates that correspond to these reduced-form estimates, we build a model economy that mirrors the geography of production networks in the United States. Within this model economy, we simulate local productivity shocks that resemble the MDP openings, providing us with a micro-level data set with "pre-" and "post-shock" observations. We then use this data set to estimate plant-level difference-in-differences regressions that mirror those in our reduced-form analysis, providing us with model-based moments and allowing us to estimate the parameters.

building blocks in quantitative spatial models.

${ }^{3}$ Our model is designed to study productivity spillovers within firms across regions, as well as their implications for the within- and across-region distribution of economic activity. This sets our model apart from a recent literature on endogenous growth that focuses on the evolution of the (national) productivity distribution through the diffusion of knowledge (e.g., Lucas and Moll, 2014; Perla and Tonetti, 2014; and the papers surveyed in Buera and Lucas, 2018). 
Given our parameter estimates, we undertake counterfactual analyses to quantify the significance of knowledge sharing through plant-level networks for the distribution of economic activity, as well as for the propagation and amplification of local productivity shocks. In one counterfactual, we increase the strength of within-firm, across-region knowledge sharing. We find that knowledge sharing between plants widens economic disparities between regions: those with high real GDP become richer, while those with low real GDP become poorer. In another counterfactual, we simulate local productivity shocks-such as those arising from place-based policies-with and without knowledge sharing between plants. While the welfare gains are $64 \%$ higher with knowledge sharing, they are not evenly distributed. In particular, workers in other regions working for plants that are "connected" (through plant-level networks) to the region with the productivity shock experience utility gains that are five times larger than workers at non-connected plants. At the regional level, we find that the welfare gains are disproportionately concentrated in highly populous regions, as those tend to have the most connected plants. Hence, knowledge sharing through plant-level networks leads to a highly uneven distribution of the welfare gains from local productivity shocks.

Our paper is related to several strands of literature. First, it is related to papers that study the aggregate implications of place-based policies. In this literature, general equilibrium effects arise from worker migration and goods trade, and possibly also from firm sorting (Busso, Gregory, and Kline, 2013; Kline and Moretti, 2014b; Gaubert, 2018; Fajgelbaum and Gaubert, 2020; Rossi-Hansberg, Sarte, and Schwartzman, 2020; Gaubert, Kline, and Yagan, 2020). Our paper focuses on a new (direct) channel through which place-based policies may affect the rest of the economy: productivity gains that spill over to other regions through the plant-level networks of multi-region firms. Unlike classical externalities from place-based policies, this externality has a positive effect on other regions. ${ }^{4}$ However, not all regions benefit equally; we find that the welfare gains are disproportionately concentrated in the most populous regions.

Relatedly, Caliendo et al. (2018) and Hornbeck and Moretti (2020) document how regional productivity shocks may impact other regions through trade flows and worker migration. Our paper focuses on productivity spillovers through the plant-level networks of multi-region firms. Our paper is also related to Bilir and Morales (2020) who, in an

\footnotetext{
${ }^{4}$ The prevailing view is that, unless workers migrate to regions with higher elasticities of productivity to agglomeration, place-based policies are at best a zero-sum game (Glaeser and Gottlieb, 2008; Moretti 2010; Kline and Moretti, 2014a). However, Fajgelbaum and Gaubert (2020) and Rossi-Hansberg, Sarte, and Schwartzman (2020) show that even when agglomeration elasticities are homogeneous, the decentralized equilibrium may be inefficient, leaving room for welfare-enhancing spatial policies. Bartelme et al. (2019) analyze optimal industrial policies at the sectoral (as opposed to regional) level.
} 
international setting, study how parent firm R\&D may affect the value added of foreign affiliates. We study a domestic setting. Moreover, we consider productivity shocks that originate outside of firms' boundaries. That being said, both papers have in common the idea that knowledge is being shared within the firm.

Finally, our paper is related to a growing literature, going back to Long and Plosser (1983) and Acemoglu et al. (2012), that studies how shocks propagate through production networks. In particular, our paper is related to a branch of this literature that considers shocks at the firm (as opposed to sectoral) level, both empirically (Barrot and Sauvagnat, 2016; Carvalho et al., 2020) and theoretically (Acemoglu and Tahbaz-Salehi, 2020). In contrast to this literature, our paper focuses on production networks within firms. ${ }^{5}$ Also, productivity spillovers in our framework are not driven by input-output linkages. On the other hand, our paper shares with the literature on production networks the idea that small shocks may propagate and have significant aggregate effects. ${ }^{6}$

The remainder of the paper is organized as follows. Section 2 provides reduced-form evidence. Section 3 develops a quantitative spatial model in which plants of multi-region firms are linked through shared knowledge. Section 4 presents the structural estimation of the model. Section 5 provides counterfactual analyses. Section 6 concludes.

\section{Reduced-Form Evidence}

\subsection{Research Design}

We examine how local productivity spillovers propagate across U.S. regions through the plant-level networks of multi-plant, multi-region manufacturing firms. To identify local productivity spillovers, we build on the natural experiments in Greenstone, Hornbeck, and Moretti (2010, GHM), who study the effects of large plant openings ("Million Dollar Plants," or MDPs) on the productivity of local incumbent plants. In their setting, plants in one or more runner-up counties, which narrowly lost the competition after surviving a long selection process, serve as a counterfactual for incumbent plants in the "winner" county, where the MDP ultimately located. ${ }^{7}$ We match the MDP openings in the Appendix

\footnotetext{
${ }^{5}$ Giroud and Mueller (2019) study an alternative channel through which establishments of the same firm may be linked: through a firm-wide financial (or budget) constraint. Focusing on large restaurant and retail (i.e., nontradable) firms during the Great Recession, they show how a drop in local consumer demand in one location tightens the firm's financial constraint and forces it to lay off employees in other locations.

${ }^{6}$ Our result that local productivity shocks may spread and amplify within firm boundaries provides a possible microfoundation for firm-level productivity shocks in granular economies (Gabaix, 2011).

${ }^{7}$ Winner and runner-up counties are from the reported location rankings of firms in the corporate real estate journal Site Selection. The journal includes a regular feature article, Million Dollar Plants, that describes
} 
of Greenstone and Moretti (2003) to plants in the Census Bureau's Standard Statistical Establishment List (SSEL) based on firm and county name. Like GHM do, we identify 11 MDP openings between 1982 and 1985, 18 MDP openings between 1986 and 1989, and 18 MDP openings between 1990 and 1993, adding up to 47 MDP openings.

We source data from three establishment-level data sets provided by the Census Bureau. The first two data sets are the Census of Manufactures (CMF) and the Annual Survey of Manufactures (ASM). They contain information about key plant-level variables, such as shipments, assets, material inputs, employment, payroll, capital expenditures, industry sector, and location. The third data set is the Longitudinal Business Database (LBD). It contains longitudinal establishment identifiers along with data on employment, payroll, industry sector, location, and firm affiliation.

We first study the ("local") spillover from the MDP openings on incumbent plants in the winner county. For each MDP opening, we identify all plants in the winner and runner-up counties. We require a plant to be present before and after the MDP opening. We use all observations from five years before until five years after, which leaves us with 157,000 plant-year observations. ${ }^{8}$ We next study the ("global") spillover on plants outside the winner county belonging to multi-county (MC) firms with plants in the winner county. To have a counterfactual for these plants, we construct various control groups. We use again all observations from five years before until five years after the MDP opening. We always exclude the MDPs themselves, as well as any plants owned by firms that own the MDPs. Depending on the control group, this leaves us with 1,407,000; 1,046,000; or 423,000 plant-year observations. The sample period is from 1977 to 1998.

Table 1 provides descriptive statistics from the year before the MDP opening. Panel A shows that the typical plant in the local spillover sample has 141.7 employees, pays an average wage of $\$ 39,530$, and its productivity (TFP) is close to the industry average. ${ }^{9}$ Panels B and C pertain to the global spillover sample with 423,000 plant-year observations. This sample is composed of plants outside the winner and runner-up (or "loser") counties that belong to MC firms with plants in the winner county ("treated plants"), as well as plants in the same counties as the treated plants belonging to MC firms with plants in the runner-up counties ("control plants"). Panel B shows that the typical plant in the global spillover sample has 268.2 employees, which is larger than in the local spillover sample, since the

\footnotetext{
where a firm decided to locate a large manufacturing plant. The feature article was last published in 1993.

${ }^{8}$ All sample sizes are rounded to the nearest 1,000 following Census Bureau disclosure guidelines.

${ }^{9}$ TFP is the estimated residual from a plant-level regression of output on capital, labor, and material inputs (all in logs). To allow for different factor intensities across industries and over time, we estimate the regression separately for each 3-digit SIC code industry and year. Accordingly, TFP can be interpreted as the relative productivity of a plant within a given industry and year.
} 
global spillover sample only includes plants of MC firms. Moreover, the typical plant in the global spillover sample pays an average wage of $\$ 38,850$, and its productivity is again close to the industry average. Finally, Panel $\mathrm{C}$ describes the parent firms associated with the plants in Panel B. As can be seen, the typical parent firm has 1,987.5 employees and 7.4 plants, which are spread out across 5.4 counties and 2.7 states.

\subsection{Local Productivity Spillover}

We first study the local productivity spillover from the MDP openings on incumbent plants in the winner county. We estimate the following specification:

$$
y_{i c k s t}=\xi_{c}+\xi_{k}+\xi_{s t}+\beta_{1} \text { Post }_{c t}+\beta_{2}\left(\text { Winner }_{i} \times \text { Post }_{c t}\right)+\varepsilon_{i c k s t},
$$

where $y_{i c k s t}$ denotes plant-level productivity (TFP), $i$ denotes counties, $c$ denotes cases, $k$ denotes plants, $s$ denotes industries, $t$ denotes years, Post $t_{c t}$ is an indicator for case $c$ from the treatment year (i.e., the year of the MDP opening) onward, Winner $r_{i}$ is an indicator for the winner county, and $\xi_{c}, \xi_{k}$, and $\xi_{s t}$ are case, plant, and industry $\times$ year fixed effects. A "case" comprises the winner county and the associated runner-up counties. The case and plant fixed effects capture time-invariant heterogeneity across cases and plants, respectively. Importantly, the case fixed effects force comparisons to be made between plants within a given winner-loser pair. The industry $\times$ year fixed effects capture time-varying shocks at the industry level. Industries are defined at the 3-digit SIC code level. The main coefficient of interest is $\beta_{2}$, which captures the mean change in productivity among plants in the winner county relative to plants in the runner-up counties.

Table 2 presents the results. In this and all other tables, we only report the main coefficient(s) of interest and write "MDP" in lieu of Winner ${ }_{i} \times$ Post $_{c t}$ for brevity. As column (1) shows, the MDP openings raise the productivity of incumbent plants in the winner county by $4 \% .{ }^{10}$ In column (2), we examine if the local productivity spillover varies with distance between the incumbent plants and the MDP. To this end, we first identify all incumbent plants within a 250 mile radius around the MDP. Naturally, this includes plants outside the winner county. We then create three dummy variables, $(<50 \text { miles })_{k}$, (50 to 100 miles $)_{k}$, and (100 to 250 miles $)_{k}$, that indicate whether the incumbent plant lies within 50 miles, between 50 and 100 miles, or between 100 and 250 miles from the MDP,

\footnotetext{
${ }^{10}$ Our estimate lies well within the range of TFP estimates reported by GHM (1.46\% to 6.13\%), albeit it is slightly lower than their baseline estimate (4.77\%). While we require plants to be present before and after the MDP opening, their baseline analysis requires plants to be present for eight consecutive years before the MDP opening. This excludes smaller plants in the ASM, which are randomly (re-)sampled every five years.
} 
and interact these dummy variables with both terms in equation (1). As is shown, the local productivity spillover decays rapidly with geographical distance. It is strong within a 50 mile radius around the MDP, much weaker within a 100 mile radius, and insignificant beyond. Hence, consistent with a large empirical literature, we find that productivity spillovers between (plants of) different firms are highly localized.

\subsection{Global Productivity Spillover}

We next study the global productivity spillover on treated plants outside the winner county that belong to firms with plants in the winner county. We estimate the same difference-in-differences specification as above, except that Winner $_{i}$ is now an indicator for whether the plant's parent firm owns a plant in the winner county, the fixed effects vary by control group, and a "case" is more generally defined as comprising all treated plants as well as all plants in the corresponding control group.

Table 3 presents the results. In column (1), the control group consists of all plants outside the runner-up counties that belong to MC firms with plants in the runner-up counties ("runner-up firms"). This specification includes plant, industry $\times$ year, and case fixed effects. Accordingly, we compare treated plants with plants of runner-up firms in the same industry and year, but possibly in different counties. In column (2), the control group consists of all plants of MC firms in the same county as the treated plant. This specification includes plant and industry $\times$ county $\times$ year fixed effects. Thus, we compare treated plants with other plants in the same county, industry, and year. This accounts for the possibility of common shocks between the county of the treated plant and the winner county, thus addressing potential concerns that the productivity gains at treated plants may be due to common regional shocks rather than internal spillovers within the firm's plant-level network. Finally, in column (3), the control group is a subset of that in column (2): it consists of all plants of runner-up firms in the same county as the treated plant. In addition to plant and industry $\times$ county $\times$ year fixed effects, this specification also includes case fixed effects. Hence, we compare plants in the same county, industry, and year that belong to parent firms which either own plants in the winner county (treatment group) or in the corresponding runner-up counties (control group).

As is shown, the MDP openings raise the productivity of treated plants outside the winner county by $1.8 \%$ to $2 \%$. The estimate is stable across specifications, despite varying control groups and fixed effects. While the productivity gains at treated plants are less than the productivity gains in the winner county, Table 1 shows that the typical "treated" MC firm has about 6.3 (treated) plants outside the winner county. Indeed, using 
a back-of-the-envelope calculation, we illustrate below that almost twice as many jobs are created outside the winner county than among all plants in the winner county combined.

\subsection{Treatment Effect Dynamics}

Table A.1 of Online Appendix A shows the dynamics of the treatment effect, both for the local and global productivity spillover. The purpose of the analysis is twofold: i) provide support for the parallel trends assumption, and ii) compare the timings of the local and global spillovers. If the productivity gains spread through firms' plant-level networks, then the global spillover should set in around the same time as (or at least not before) the local spillover. As is shown, there are no significant differences in pre-trends between either plants in the winner and runner-up counties, or between treated plants and plants of runner-up firms in the same county as the treated plant. Furthermore, the global productivity spillover sets in around the same time as the local productivity spillover. In either case, the estimates remain economically large and stable until the end, suggesting that the productivity gains are not temporary.

\subsection{Mechanism}

Marshall (1890) famously divides agglomeration economies into three categories: i) labor market pooling, ii) knowledge spillovers, and iii) input-output linkages. Using various measures of economic distance between the MDP and the incumbent plants, GHM find that the local productivity spillover is consistent with either labor market pooling or knowledge spillovers, but not with input-output linkages. ${ }^{11}$

While labor market pooling and knowledge spillovers may both contribute to the local productivity spillover, it is unlikely that a larger labor market in the winner county would affect the productivity of distant plants hundreds of miles away. Knowledge, on the other hand, can be used in local and distant plants alike. Indeed, once it spills over to the firm's local plant, it can be freely shared with other plants inside the firm's boundaries

\footnotetext{
11 " $[\mathrm{T}]$ his evidence is consistent with intellectual externalities to the extent that they are embodied in workers who move from firm to firm and to the extent that they occur among firms that use technologies that are reasonably similar. The estimates ... seem less consistent with the hypothesis that agglomeration occurs because of proximity to customers and suppliers” (p. 577). In Tables A.2 and A.3 of Online Appendix A, we confirm that input-output linkages play no significant role for either the local or global productivity spillover. This also addresses the possibility that the global productivity spillover may be driven by local demand from the MDP, which in turn relaxes firm-wide financial constraints and thereby benefits distant plants. To further explore this hypothesis, we have examined if the global productivity spillover is stronger for more financially constrained firms. As Tables A.4 and A.5 of Online Appendix A show, firm-wide financial constraints play no significant role for either the local or global productivity spillover.
} 
(Markusen, 1984). To explore this issue, we examine if the global productivity spillover becomes weaker as we increase the distance to the MDP. Table 4 shows the results. Based on our tightest specification in column (3) of Table 3, we exclude all plants within a 100 mile, 250 mile, or 500 mile radius around the MDP (columns (1) to (3)), or in the same state or Census division as the MDP (columns (4) and (5)). As is shown, the estimates are stable and practically identical to the original estimate in column (3) of Table 3. Hence, unlike the local productivity spillover, which takes place across plants of different firms, the global productivity spillover, which takes place across different plants of the same firm, does not decay with geographical distance.

Why is the local productivity spillover twice as large as the global productivity spillover? ${ }^{12}$ For one, not all of the productivity gains in the winner county may be due to knowledge spillovers. As noted above, they are likely due to both knowledge spillovers and thicker labor markets. Furthermore, some knowledge may not be passed on to other plants of the firm, as it may be location-specific or difficult to share ("soft information"). In contrast, knowledge about specific products or production processes is likely relevant for, and easier to share with, other plants of the firm. We explore this idea in columns (1) and (2) of Table 5 by interacting both terms in equation (1) with indicators for whether the treated plant is in the same 4-digit SIC code industry as either the MDP or the firm's plant in the winner county. The 4-digit industry classification is extremely fine; it comprises 459 manufacturing industries in the CMF/ASM. Plants in the same 4-digit industry produce similar goods and use similar production processes. For example, "nitrogenous fertilizers" (SIC 2873), "phosphatic fertilizers" (SIC 2874), and "fertilizers, mixing only" (SIC 2875) all have different 4-digit SIC codes. As is shown, the global productivity spillover is much stronger if the treated plant and either the MDP or the firm's plant in the winner county are in the same narrow industry.

Finally, in columns (3) to (6), we interact both terms in equation (1) with measures of knowledge sharing at the industry-pair level. The first measure, "mutual R\&D flows," captures how R\&D in one industry flows out to benefit another industry. The second measure, "mutual patent citations," captures the extent to which technologies associated with one industry cite technologies associated with another industry. ${ }^{13}$ In either case, we measure the extent of knowledge sharing between the industry of the treated plant and

\footnotetext{
${ }^{12}$ This is true even if we estimate the local productivity spillover using only plants of MC firms. Their productivity gain in the winner county is $3.9 \%$, which is twice as large as outside the winner county.

${ }^{13}$ The measures of mutual R\&D flows and patent citations are the unidirectional measures Tech $_{i j} \equiv$ $\max \left\{\operatorname{TechIn}_{i \leftarrow j}\right.$, TechOut $\left._{i \rightarrow j}\right\}$ and Patent ${ }_{i j} \equiv \max \left\{\right.$ PatentIn $_{i \leftarrow j}$, PatentOut $\left.{ }_{i \rightarrow j}\right\}$ at the 3-digit SIC code level from Ellison, Glaeser, and Kerr (2010). As the authors note (p. 1202): "we base our metrics of information flows on patents and research and development (R\&D), which reflect only the highest level of information flows."
} 
either the industry of the MDP or the industry of the firm's plant in the winner county. As is shown, the global productivity spillover is much stronger if the treated plant and either the MDP or the firm's plant in the winner county are in (knowledge-based) industries characterized by mutual R\&D flows or patent citations. ${ }^{14}$ The effects are economically significant. For instance, in column (3), a one-standard deviation increase in the R\&D flow measure $(0.022)$ raises the productivity gains at treated plants by 1.3 percentage points.

\subsection{Employment and Wages}

We finally study the implications for employment and wages. Table 6 examines the local employment and wage spillovers in the winner county. As can be seen, employment and wages increase by $3.5 \%$ and $3.7 \%$, respectively, which is of the same order of magnitude as the productivity gains. ${ }^{15}$ Table 7 examines the global employment and wage spillovers. As is shown, employment at treated plants increases by $1.6 \%$ to $1.7 \%$, which is again of the same order of magnitude as the productivity gains. ${ }^{16}$ However, wages only increase by a small amount. This is not surprising; in any given county outside the winner county, only relatively few plants are treated, putting only mild pressure on local wages.

With the usual caveats, we can perform a simple back-of-the-envelope calculation to determine the total number of jobs created outside the winner county versus those created in the winner county. In the winner county, about 52,600 workers are employed in manufacturing prior to the MDP opening. By comparison, about 211,900 workers are employed at treated plants outside the winner county. Given the estimates in Tables 6 and 7 , this implies that $0.035 \times 52,600=1,841$ jobs are created in the winner county versus $0.016 \times 211,900=3,390$ jobs outside the winner county. Hence, almost twice as many jobs are created outside the winner county than at all plants in the winner county combined.

\section{Theoretical Framework}

We develop a quantitative spatial model to quantify the impact of knowledge sharing through plant-level networks on sub-regional, regional, and aggregate outcomes. At the

\footnotetext{
${ }^{14}$ Table A.6 of Online Appendix A applies the tests from Table 5 to the local productivity spillover. The results mirror those in Table 5.

${ }^{15}$ The increase in employment is much larger when the MDP itself is included. Using county-level data, which includes the MDP, Monte, Redding, and Rossi-Hansberg (2018) find that employment in the winner county increases by $5.7 \%$ after the MDP opening. Indeed, GHM (Table 1) note that the average MDP is large relative to the rest of the winner county-it accounts for $8.6 \%$ of total output one year before the MDP opening.

${ }^{16}$ Table A.7 of Online Appendix A shows that the employment effects do not decay with geographical distance to the MDP.
} 
regional level, our model resembles a canonical Armington model in which regions are linked through goods trade and labor mobility (Armington, 1969; Anderson, 1979; Allen and Arkolakis, 2014). We extend the model to include finitely many plants in each region. Plants can either be stand-alone ("single-county plant" or "SC plant") or belong to a parent firm which has plants in other locations ("multi-county plant" or "MC plant"). Plants' productivities depend on local knowledge; MC plants' productivities additionally depend on knowledge in other regions in which the parent firm has a plant. This induces direct productivity linkages across regions and heterogeneity in plants' productivities within a region. At the sub-regional level, our production technology is reminiscent of Eaton and Kortum (2002) and similar Ricardian models. The main difference is that, in our model, multiple plants in each location produce a location-specific continuum of intermediate goods instead of multiple countries producing an economy-wide continuum. ${ }^{17}$ Moreover, we extend traditional preferences over locations to preferences over both locations and plants within a location. In equilibrium, this induces plants in the same location to pay different wages; in particular, more productive plants pay higher wages. Altogether, our model includes classical Armington model forces at the regional level; Ricardian model forces at the sub-regional level, plant-level network-based productivity linkages across regions; and within-location heterogeneity in productivity, employment, and wages.

\subsection{Primitives}

Our model economy consists of $N$ heterogeneous regions (also "locations" or "counties") which interact through trade in goods markets and labor mobility. Locations, denoted by $i, n, \ell$, exogenously differ from one another with regard to knowledge stock, land supply, amenities, and the spatial allocation of intermediate goods producers. We refer to intermediate goods producers as plants. Plants are organized into $J$ networks which we call firms, denoted by $j, k$. $J^{S C}$ firms consist of a single plant ("single-county firms" or "SC firms"), while $J^{M C}$ firms have plants in multiple counties ("multi-county firms" or "MC firms"). Each county has at least one SC plant, and each MC firm has at most one plant per county. We refer to individual plants by their location-firm tuple $\{i, j\}$. Let $\mathcal{E}_{j}$ be the set of locations in which firm $j$ has a plant, and let $\mathscr{E}_{i}$ be the set of firms with a plant in location $i$. Plant $\{i, j\}$ 's productivity depends on location $i$ 's knowledge as well as knowledge in all other locations in $\mathcal{E}_{j}$. Plants in each region produce a region-specific

\footnotetext{
${ }^{17}$ When combined with the rest of our model, this difference allows us to separate the calculation of the across-location equilibrium from the calculation of the within-location equilibrium, which greatly simplifies the computational and analytical characterizations of the model equilibrium and its inversion.
} 
continuum of intermediate goods, which is aggregated by final goods producers, and then shipped to, and consumed by, consumers in all regions.

\subsection{Consumer Preferences}

Workers are geographically mobile and endowed with one unit of labor each that is inelastically supplied. Worker $\eta$ working for plant $\{n, j\}$ earns wage $w_{n j}$ and derives utility from goods consumption $\left(C_{\eta}\right)$, residential land use $\left(h_{\eta}\right)$, and plant-level idiosyncratic amenities $\left(b_{n j \eta}\right)$ :

$$
u_{n j \eta}=b_{n j \eta}\left(\frac{C_{\eta}}{\alpha}\right)^{\alpha}\left(\frac{h_{\eta}}{1-\alpha}\right)^{1-\alpha}
$$

where $\alpha \in(0,1)$ and $b_{n j \eta}$ is drawn from a multivariate Fréchet distribution given by:

$$
\mathbb{P}\left(\bigcap_{n=1}^{N} \bigcap_{j \in \mathscr{E}_{n}}\left\{b_{n j} \leq t_{n j}\right\}\right)=\exp \left\{-\sum_{n \in N}\left(\sum_{j \in \mathscr{E}_{n}} B_{n}^{\frac{1}{1-\rho}} t_{n j}^{-\frac{\epsilon}{1-\rho}}\right)^{1-\rho}\right\}
$$

for all $\left\{t_{n j}\right\}_{n \in N: j \in \mathscr{E}_{n}} \in[0, \infty)^{\sum_{n}\left|\mathscr{E}_{n}\right|}$. The amenity scale parameter $B_{n}$ indexes the average draw of idiosyncratic utility for plants in location $n$. The amenity shape parameter $\epsilon>1$ controls dispersion in idiosyncratic draws across locations; as $\epsilon \rightarrow \infty$, the distribution degenerates to a set of mass points ordered by $\left\{B_{n}\right\}_{n \in N}$. Finally, the amenity correlation parameter $\rho \in[0,1)$ controls the strength of the correlation of within-location, across-plant idiosyncratic utility draws.

Consumers have CES preferences over final goods sourced from each location with an elasticity of substitution equal to $\sigma$ :

$$
C_{\eta}=\left(\sum_{i \in N} c_{i \eta}^{\frac{\sigma-1}{\sigma}}\right)^{\frac{\sigma}{\sigma-1}}
$$

where $c_{i \eta}$ is the amount of location $i$ 's final good consumed by consumer $\eta$.

\subsection{Production Technology}

Perfectly competitive plants located in county $i$ produce a location-specific continuum of intermediate goods $\omega_{i} \in[0,1]$ with technology $q_{i j}\left(\omega_{i}\right)=z_{i j}\left(\omega_{i}\right) l_{i j}\left(\omega_{i}\right)$, where $z_{i j}\left(\omega_{i}\right)$ and $l_{i j}\left(\omega_{i}\right)$ are plant $\{i, j\}$ 's (idiosyncratic) productivity and labor, respectively, for producing good $\omega_{i}$. We assume $\frac{1}{z_{i j}\left(\omega_{i}\right)}$ is a Pareto distributed random variable with productivity scale 
parameter $\frac{1}{\bar{z}_{i j}}$ and common productivity shape parameter $v \cdot{ }^{18}$ We assume idiosyncratic productivity draws which are independent across plants and intermediate goods. Plants take their wage $w_{i j}$ and productivity distribution as given.

Perfectly competitive final goods producers use intermediate goods to make the location-specific final good and ship it to all regions for consumption. Final goods producers use equal quantities of each intermediate good to assemble the final good. Goods trade is subject to bilateral "iceberg" trade costs such that $\tau_{n i} \geq 1$ units must be shipped from location $i$ in order for one unit to arrive in location $n$. Final goods producers' marginal cost is thus the product of trade costs and the average production cost of intermediate goods. We assume trade is frictionless within a location, $\tau_{n n}=1$. Across locations, for our estimation, we parameterize trade costs as a constant elasticity function of haversine distance between country centroids, $\tau_{n i}=\tau_{n i}=$ dist $_{n i}^{\psi}$.

\subsection{Knowledge and Productivity}

We assume plants' productivity scale parameters depend on exogenous knowledge and endogenous agglomeration economies that depend on local population size $L_{i}{ }^{19}$ Specifically, building on Markusen (1984), we assume plants draw on firm-wide shared knowledge (or "knowledge capital"):

$$
\bar{z}_{i}^{j}=K_{i}\left(K_{-i}^{j}\right)^{\theta} L_{i}^{\beta}
$$

where $K_{i}$ is knowledge in county $i, K_{-i}^{j}$ represents firm $j$ 's knowledge from its other plants, and $L_{i}^{\beta}$ represents classical, local agglomeration economies.

For MC firms, we assume $K_{-i}^{j}$ is the geometric mean of knowledge in the other locations in which the firm operates:

$$
K_{-i}^{j}=\Pi_{\ell \in \mathcal{E}_{j} \backslash\{i\}} K_{\ell}^{\frac{1}{\left|\mathcal{E}_{j}\right|-1}}
$$

For SC firms, which operate in a single location, we set $K_{-i}^{j}=1$, in which case equation (5) reduces to $\bar{z}_{i}^{j}=K_{i} L_{i}^{\beta}$. In counties with only SC plants, our productivity process is thus similar to a standard Armington model. By contrast, counties with MC plants are connected to other counties through a knowledge-sharing network allowing for direct

\footnotetext{
${ }^{18}$ We employ the inverse Pareto distribution for two reasons: (1) closed-form expressions for realized productivity and labor shares, and (2) to allow plants to produce with heterogeneous realized productivity.

${ }^{19}$ Plant output is thus a function of both labor and knowledge, as in Caliendo and Rossi-Hansberg (2012) and Caliendo, Monte, and Rossi-Hansberg (2015).
} 
productivity spillovers across locations, in line with our global spillover estimates. The key parameter which controls the strength of within-firm, across-location productivity spillovers is the "knowledge-sharing parameter" $\theta$. Ceteris paribus, a higher $\theta$ puts more weight on knowledge in the other locations in which the firm operates.

\subsection{Solution to Consumer Problem}

\subsubsection{Goods and Housing}

Consider consumer $\eta$ in location $n$. Standard CES demand results give us:

$$
c_{i \eta}=x_{\eta} p_{n i}^{-\sigma} P_{n}^{\sigma-1}
$$

where $x_{\eta}$ is the amount consumer $\eta$ spends on goods, $p_{n i}$ is the price of final goods shipped from location $i$ to location $n$, and $P_{n}$ is the Dixit-Stiglitz price index:

$$
P_{n} \equiv\left(\sum_{i \in N}\left(p_{n i}\right)^{1-\sigma}\right)^{\frac{1}{1-\sigma}}
$$

Consumption choices aggregate such that:

$$
c_{n i}=X_{n} p_{n i}^{-\sigma} P_{n}^{\sigma-1}
$$

where $c_{n i}$ is the quantity of location $i$ 's final good consumed in location $n$, and $X_{n}$ is total expenditure on consumption in location $n$.

We assume that land is inelastically supplied and owned by immobile landlords, who receive land rents $R_{n}$ from workers as income and consume their local consumption bundle (see Monte, Redding, and Rossi-Hansberg, 2018). Cobb-Douglas preferences across goods and land imply that the expenditure share of labor income on land consumption is given by $(1-\alpha) .{ }^{20}$ Total labor income is the product of average wages $W_{n}$ and local population $L_{n}$. Land market clearing implies that equilibrium land rents are given by:

$$
R_{n}=\frac{(1-\alpha) W_{n} L_{n}}{H_{n}}
$$

Our assumptions on competition and landlords' consumption imply that total consumption expenditures in each location equal total labor income, which in turn equals total expenditures on goods produced in that location:

\footnotetext{
${ }^{20}$ See Davis and Ortalo-Magné (2011) for evidence in support of the constant housing expenditure share implied by the Cobb-Douglas representation in equation (2).
} 


$$
L_{n} W_{n}=\sum_{i \in N} p_{i n}^{1-\sigma} P_{i}^{\sigma-1} L_{i} W_{i}
$$

\subsubsection{Location Choice and Welfare}

Each worker chooses a plant that maximizes her utility. Worker $\eta$ 's indirect utility from working for plant $\{n, j\}$ is given by $b_{n j \eta} \frac{w_{n j}}{P_{n}^{\alpha} R_{n}^{1-\alpha}}$. In the spirit of McFadden (1978), worker $\eta$ faces a nested choice; we can decompose this choice problem into a choice of location $n$ and, within location $n$, a choice of plant $j \in \mathscr{E}_{n}$. Using results from Lind and Ramondo (2021), we show in Online Appendix B.1 that the labor share of location $n$ is given by:

$$
\frac{L_{n}}{\bar{L}} \equiv \mathbb{P}\{\eta \text { chooses } n\}=\frac{B_{n}\left(\frac{W_{n}^{b}}{P_{n}^{\alpha} R_{n}^{1-\alpha}}\right)^{\epsilon}}{\sum_{\ell \in N} B_{\ell}\left(\frac{W_{\ell}^{b}}{P_{\ell}^{\alpha} R_{\ell}^{1-\alpha}}\right)^{\epsilon}},
$$

where the "amenity wage" $W_{n}^{b}$ is an aggregator of plant-level wages in location $n$ :

$$
W_{n}^{b}:=\left(\sum_{j \in \mathscr{C}_{n}} w_{n j}^{\frac{\epsilon}{1-\rho}}\right)^{\frac{1-\rho}{\epsilon}}
$$

Furthermore, Online Appendix B.1 shows that within-location (supply-side) labor shares are given by:

$$
\frac{l_{n j}^{S}}{L_{n}}=\mathbb{P}\{\eta \text { chooses } j \mid \eta \text { chooses } \mathrm{n}\}=\frac{w_{n j}^{\frac{\epsilon}{1-\rho}}}{\sum_{k: n \in \mathcal{E}_{k}} w_{n k}^{\frac{\epsilon}{1-\rho}}}
$$

where $l_{n j}^{S}$ represents labor supplied to plant $\{n, j\}$ given plant-level wages $\left\{w_{n k}\right\}_{k \in \mathscr{E}_{n}}$. Plants face an upward-sloping labor supply curve. To attract additional workers with lower idiosyncratic preference draws, real wages $w_{n j} /\left(P_{n}^{\alpha} R_{n}^{1-\alpha}\right)$ must increase. When plant $\{n, j\}$ 's real wage increases, if $\rho>0$, it attracts workers from both within location $n$ and other locations. As $\rho \rightarrow 1$, within-location preferences become perfectly correlated.

In Online Appendix B.1, we show average realized utility, or welfare, is given by:

$$
\bar{U}=\Gamma\left(\frac{\epsilon-1}{\epsilon}\right)\left[\sum_{n \in N} B_{n}\left(\frac{W_{n}^{b}}{P_{n}^{\alpha} R_{n}^{1-\alpha}}\right)^{\epsilon}\right]^{\frac{1}{\epsilon}},
$$

where $\Gamma(\cdot)$ denotes the gamma function. 


\subsection{Solution to Producer Problem}

\subsubsection{Plant Production}

Under perfect competition, each intermediate good is produced by the plant with the lowest marginal cost. We show in Online Appendix B.1 that within-location (demand-side) labor shares are given by:

$$
\frac{l_{i j}^{D}}{L_{i}}=\mathcal{L} \mathcal{D}_{i j}\left(v,\left\{\bar{z}_{i k}, w_{i k}\right\}_{k \in \mathscr{E}_{i}}\right),
$$

where $l_{i j}^{D}$ represents labor demand by plant $\{i, j\}$ given productivity scale parameters and wages $\left\{\bar{z}_{i k}, w_{i k}\right\}_{k \in \mathscr{C}_{i}} . \mathcal{L} \mathcal{D}_{i j}$ is homogeneous of degree zero and exhibits gross substitution in both productivity scale parameters and wages. ${ }^{21} \mathcal{L} \mathcal{D}_{i j}$ is also strictly greater than zero, which ensures that all plants produce in equilibrium. ${ }^{22}$ Finally, $v$ controls the elasticity of $\mathcal{L} \mathcal{D}_{i j}$ with respect to both productivity scale parameters and wages ; as $v$ increases, labor demand becomes more elastic. We provide the exact form of $\mathcal{L} \mathcal{D}_{i j}$ in Online Appendix B.1.

We also show in Online Appendix B.1 that plants produce with realized average productivity $\hat{z}_{i j}$ given by:

$$
\hat{z}_{i j} \equiv \mathbb{E}\left[z_{i j}\left(\omega_{i}\right) \mid j \text { produces } \omega_{i}\right]=\mathbb{E}\left[z_{i j}\left(\omega_{i}\right)\right] \mathcal{R} \mathcal{S}_{i j}\left(v,\left\{\frac{\bar{z}_{i k}}{w_{i k}}\right\}_{k \in \mathscr{C}_{i}}\right),
$$

where $\mathbb{E}\left[z_{i j}\left(\omega_{i}\right)\right]=\frac{v}{v+1} \bar{z}_{i j}$ is finite for all $v>0 . \mathcal{R} \mathcal{S}_{i j}$ denotes Ricardian spillovers capturing productivity gains from comparative advantage across plants. It is bounded between 1 and $\frac{v+1}{v}$, homogeneous of degree zero in wage-adjusted productivity scale parameters $\left\{\frac{\bar{z}_{i k}}{w_{i k}}\right\}_{k \in \mathscr{E}_{i}}$, decreasing in $v$, increasing in $\left|\mathscr{E}_{i}\right|$, and decreasing in $\frac{\bar{z}_{i j}}{w_{i j}}$. We provide the exact form of $\mathcal{R} \mathcal{S}_{i j}$ in Online Appendix B.1.

\subsubsection{Final Goods Production}

Since plants and final goods producers are perfectly competitive, final goods are supplied at marginal cost. This implies:

\footnotetext{
${ }^{21}$ In our model, gross substitution in productivity scale parameters is equivalent to $\frac{\partial \mathcal{L} \mathcal{D}_{i j}}{\partial \bar{z}_{i j}}>0$ and $\frac{\partial \mathcal{L} \mathcal{D}_{i j}}{\partial \bar{z}_{i k}}<$ $0 \forall k \in \mathscr{E}_{i} \backslash\{j\}$; gross substitution in wages is equivalent to $\frac{\partial \mathcal{L} \mathcal{D}_{i j}}{\partial w_{i j}}<0$ and $\frac{\partial \mathcal{L} \mathcal{D}_{i j}}{\partial w_{i k}}>0 \forall k \in \mathscr{E}_{i} \backslash\{j\}$

${ }^{22}$ This is different from models of granular firms in international trade (e.g., Eaton, Kortum, and Sotelo, 2012; Gaubert and Itskhoki, 2021), where only a subset of firms produces in equilibrium. In our (domestic) setting, it is crucial that all plants produce in equilibrium in order to mimick the economic footprints of plant-level networks in Census data.
} 


$$
p_{n i}=m c_{n i} \equiv \tau_{n i} \int_{0}^{1} m c_{i}\left(\omega_{i}\right) d \omega_{i}=W_{i}^{z} \tau_{n i},
$$

where $m c_{i}\left(\omega_{i}\right)$ is the marginal cost to supply intermediate good $\omega_{i}$ and the (Marshallian) "efficiency wage" $W_{i}^{z}$ captures the average cost to produce one unit of output. Without dispersion in wages, we would have $W_{i}^{z}=W_{i} \mathbb{E}\left[\min _{j} \frac{1}{z_{i}^{j}\left(\omega_{i}\right)}\right]$. However, because more productive plants will offer higher wages in equilibrium, the formula is somewhat more subtle in our case. We show in Online Appendix B.1 that:

$$
W_{i}^{z}=\mathcal{Z}\left(v,\left\{\frac{\bar{z}_{i j}}{w_{i j}}\right\}_{j \in \mathscr{E}_{i}}\right),
$$

where the productivity aggregator $\mathcal{Z}$ is homogeneous of degree -1 , decreasing in wage-adjusted productivity scale parameters, and decreasing in $\left|\mathscr{E}_{i}\right|$. The parameter $v$ controls the relative importance of efficient and inefficient plants; as $v$ increases, plants with a higher wage-adjusted productivity scale parameter become relatively more important. We provide the exact form of $\mathcal{Z}$ in Online Appendix B.1.

\subsection{General Equilibrium}

Define the following endogenous objects: within-location labor shares $l:=\left\{\frac{l_{n j}}{L_{n}}\right\}_{n \in N: j \in \mathscr{C}_{n}}$, within-location relative wages $\boldsymbol{w}:=\left\{\frac{w_{n j}}{W_{n}}\right\}_{n \in N: j \in \mathscr{C}_{n}}$, county-level labor $\boldsymbol{L}:=\left\{L_{n}\right\}_{n \in N}$, and county-level average wages $\boldsymbol{W}:=\left\{W_{n}\right\}_{n \in N}$. Moreover, define the following exogenous fundamentals: land endowments $\boldsymbol{H}:=\left\{H_{n}\right\}_{n \in N}$, amenity scale parameters $\boldsymbol{B}:=\left\{B_{n}\right\}_{n \in N}$, knowledge $\boldsymbol{K}:=\left\{K_{n}\right\}_{n \in N}$, plant-level networks $\mathcal{E}:=\left\{\mathcal{E}_{j}\right\}_{j \in J}$, and bilateral trade costs $\tau:=\left\{\tau_{n i}\right\}_{\{n, i\} \in N^{2}}$.

We are ready to characterize equilibria of our model. Equilibrium labor allocations and wages $\{\boldsymbol{l}, \boldsymbol{w}, \boldsymbol{L}, \boldsymbol{W}\}$ are pinned down by equations (11) (total expenditure equals labor income), (12) (county-level labor shares), (14) (within-location (supply-side) labor shares), and (16) (within-location (demand-side) labor shares). Further, if $\{\boldsymbol{l}, \boldsymbol{w}, \boldsymbol{L}, \boldsymbol{W}\}$ solve all four equations, there exists an equilibrium with those labor allocations and wages and, given fundamentals $\{\boldsymbol{H}, \boldsymbol{B}, \boldsymbol{K}, \mathcal{E}, \boldsymbol{\tau}\}$, we can recover the equilibrium values of all endogenous objects in closed form. We thus refer to equilibria by their corresponding labor allocations and wages, $\{\boldsymbol{l}, \boldsymbol{w}, \boldsymbol{L}, \boldsymbol{W}\}$.

Proposition 1. Given parameter values $\{\alpha, \beta, \sigma, \epsilon, \theta, v, \rho\}$ and fundamentals $\{\boldsymbol{H}, \boldsymbol{B}, \boldsymbol{K}, \mathcal{E}, \boldsymbol{\tau}\}$, if $\frac{\alpha \epsilon-\epsilon-1}{\alpha \epsilon}+\beta \leq 0$ and $\frac{1+\sigma \beta+(\sigma-1) \frac{\alpha \epsilon-\epsilon-1}{\alpha \epsilon}}{1+\beta(1-\sigma)-\sigma \frac{\alpha \epsilon-\epsilon-1}{\alpha \epsilon}} \in[-1,1]$, the equilibrium of 
the model exists and is unique (up to a normalization in wages).

Proof. See Online Appendix B.2.

The first condition in Proposition (1) guarantees that dispersion forces are (weakly) stronger than agglomeration forces. The second condition is the same condition as in Theorem 2 of Allen and Arkolakis (2014), subject to a relabeling of the parameters. ${ }^{23}$ The proof of Proposition (1) hinges critically on the separability of the within-location equilibrium conditions from the across-location equilibrium conditions. We first prove that each location has unique within-location labor shares and relative wages satisfying equations (14) and (16). We then show that the unique within-location solution implies that, in equilibrium, efficiency wages and amenity wages are linear functions of average wages. Finally, using the linearity of efficiency wages and amenity wages, if the sufficient conditions in Proposition (1) hold, we prove the existence of unique vectors of county-level employment and (up to a normalization) county-level average wages satisfying equations (11) and (12). In the final step of the proof, we show that the across-location equilibrium conditions are isomorphic to (a discretized version of) the equilibrium conditions in Allen and Arkolakis (2014) and apply the main theorem from Allen, Arkolakis, and Li (2020). ${ }^{24}$

\subsection{Model Inversion}

The following proposition shows that the model can be inverted to recover unique (up to a normalization) values of $\{\boldsymbol{B}, \boldsymbol{K}\}$ and $\{\boldsymbol{l}, \boldsymbol{w}\}$ which are consistent with the observed distribution of economic activity.

Proposition 2. Given parameter values $\{\alpha, \beta, \sigma, \epsilon, \theta, v, \rho\}$, fundamentals $\{\boldsymbol{H}, \mathcal{E}, \boldsymbol{\tau}\}$, and observed data $\{\boldsymbol{L}, \boldsymbol{W}\}$, if $\theta<1$, there exist unique (up to a normalization) unobserved fundamentals $\{\boldsymbol{B}, \boldsymbol{K}\}$ and plant-level distributions of employment and wages $\{\boldsymbol{l}, \boldsymbol{w}\}$ that rationalize the data as an equilibrium of the model.

Proof. See Online Appendix B.2.

We first prove that, given parameter values, fundamentals, and observed data, there exist unique (up to a normalization) efficiency wages that satisfy equation (11) (total expenditure

\footnotetext{
${ }^{23}$ Allen and Arkolakis (2014) show that for certain parameter values the second condition is implied by the first.

${ }^{24}$ Allen and Arkolakis (2014, Online Appendix A.2) in turn show that their model is isomorphic to a broad class of gravity models, including models with exogenous entry (e.g., Eaton and Kortum, 2002; Melitz, 2003, as considered in Chaney, 2008) and free entry (e.g., Krugman, 1980; Melitz, 2003, as considered in Arkolakis et al., 2008), as well as economic geography models (e.g., Redding, 2016).
} 
equals labor income). We then invert the formula for efficiency wages (equation (19)) to provide a recursive formulation for unobserved knowledge. We prove that, if $\theta<1$, this recursive formulation is a contraction mapping. This implies the existence of a unique vector of unobserved knowledge that generates the recovered efficiency wages, which in turn uniquely pins down the plant-level distributions of employment and wages. We finally show that there exist unique (up to a normalization) amenity scale parameters that satisfy equation (12) (location labor shares).

\section{Structural Estimation}

\subsection{Model Economy}

We simulate an economy with a large number of locations, plants, and firms that mirrors the geography of production networks in U.S. Census data. Each location $n=1, \ldots, N$ corresponds to a specific county. We assign each county its actual geographical coordinates and land area using information from the U.S. Gazetteer Files provided by the Census Bureau. Moreover, we assign each county its actual manufacturing employment and wages using 1987 Census data. We use data from 1987 as our estimation targets reduced-form estimates based on the MDP openings, which took place between 1982 and 1993.

We populate the economy with SC and MC plants and firms as in 1987 Census data. Key for our estimation and counterfactuals is the spatial allocation of MC plants. We assign MC plants to counties by matching their empirical distribution in Census data. As Figure 1 shows, this distribution is heavily skewed. While about $60 \%$ of MC plants are located in the $10 \%$ most populous counties, the $50 \%$ least populous counties have only about $7 \%$ of MC plants. We assign MC plants to firms based on their empirical distribution in Census data. As plants in our model are uniquely identified by their location and firm affiliation, we assume that any given MC firm has at most one plant per location. Also, we assume SC firms are single-plant firms. ${ }^{25}$ Overall, our model economy consists of 328,000 plants. ${ }^{26}$

\footnotetext{
${ }^{25}$ The ratio of SC plants to firms in the 1987 CMF is 1.01 ; thus, practically all SC firms are single-plant firms.

${ }^{26}$ Our model economy has 275,000 SC plants and 53,000 MC plants, exactly as in the 1987 CMF. Figure A.1 of Online Appendix A shows that our model economy implies a realistic geography of manufacturing activity. As in the data, most manufacturing plants are located in the North East, the Rust Belt, and along the West coast, and to a lesser extent in the South East.
} 


\subsection{Parameters}

We divide the parameters, $\Theta:=\{\alpha, \beta, \psi, \sigma, \epsilon, \theta, v, \rho, \kappa\}$, into two sets. The first consists of parameters which we calibrate using values from the literature. We set the share of housing in consumer expenditure $(1-\alpha)$ equal to 0.34 (Davis and Ortalo-Magné 2011; Monte, Redding, and Rossi-Hansberg, 2018), the elasticity of local firm productivity to agglomeration $(\beta)$ equal to 0.023 (Gaubert, 2018), the elasticity of trade cost to distance $(\psi)$ equal to 0.43 (Monte, Redding, and Rossi-Hansberg, 2018), the elasticity of substitution $(\sigma)$ equal to 4 (Bernard et al., 2003; Broda and Weinstein, 2006; Redding, 2016), and the amenity shape parameter $(\epsilon)$ equal to 3 (Redding, 2016; Bryan and Morten, 2019). The second set consists of parameters which have no direct counterpart in the literature, and which we therefore estimate: the knowledge-sharing parameter $\theta$, the (Pareto) productivity shape parameter $v$, the amenity correlation parameter $\rho$, and the parameter $\kappa$ described below.

\subsection{Micro-Level Data Set}

Our model features within-region, across-plant heterogeneity. Hence, plant-level micro moments are necessary to identify the parameters. To this end, we employ an indirect inference approach and target as moments reduced-form estimates-semi-elasticities of plant-level employment, wages, and productivity to the MDP openings-that are informative about plant-level outcomes. To obtain model-based estimates that correspond to these reduced-form estimates, we simulate local productivity shocks that resemble the MDP openings. This provides us with a micro-level data set with "pre-" and "post-shock" observations, allowing us to estimate plant-level difference-in-differences regressions that closely mirror those in our reduced-form analysis. We construct the data set in two steps. Further details are provided in Online Appendix C.

Step 1. Pre-Shock Equilibrium and Recovery of Fundamentals. Given parameter values and observed fundamentals, we recover the unobserved fundamentals and plant-level distributions of employment and wages that rationalize the data as an equilibrium of the model. Specifically, we assign each county its employment, wages, and observed fundamentals using Census data. We then invert the equilibrium conditions of the model and use its recursive structure to recover the unobserved county-level fundamentals (amenity scale parameters and knowledge) and within-county plant-level distributions of employment and wages that rationalize the data as an equilibrium of the model.

Definition 1. Given parameter values $\Theta$ and fundamentals $\{\boldsymbol{H}, \boldsymbol{B}(\boldsymbol{\Theta}), \boldsymbol{K}(\boldsymbol{\Theta}), \boldsymbol{\mathcal { E }}, \boldsymbol{\tau}(\psi)\}$, the pre-shock equilibrium is given by $\{\boldsymbol{L}, \boldsymbol{W}, \boldsymbol{l}(\boldsymbol{\Theta}), \boldsymbol{w}(\Theta)\}$. 
We explicitly write $\boldsymbol{B}(\Theta), \boldsymbol{K}(\Theta), \boldsymbol{l}(\Theta)$, and $\boldsymbol{w}(\Theta)$ as a reminder that the unobserved county-level fundamentals $\{\boldsymbol{B}, \boldsymbol{K}\}$ and within-county plant-level distributions $\{\boldsymbol{l}, \boldsymbol{w}\}$ are functions of the parameters to be estimated. Proposition 2 shows that the model can be inverted to recover unique (up to a normalization) values of $\{\boldsymbol{B}, \boldsymbol{K}\}$ and $\{\boldsymbol{l}, \boldsymbol{w}\}$.

Step 2. Post-Shock Equilibrium. The second step involves re-computing the endogenous objects after perturbing the pre-shock equilibrium with local productivity shocks that resemble the MDP openings. Specifically, we randomly select 47 winner and runner-up county pairs from the top quintile of the population distribution (as in the actual MDP openings) and assume the MDP openings increase log local knowledge $K_{i}$ in the winner county by $\kappa$. The parameter $\kappa$, which measures the semi-elasticity of knowledge in the winner county to the MDP openings, is jointly estimated with the other parameters. For each MDP opening, we compute the post-shock equilibrium implied by the reallocation of economic activity under the new distribution of knowledge. Precisely, holding fixed all parameters and fundamentals (except in the winner county, where $K_{i}$ increases) at their pre-shock values, we solve for the unique county- and plant-level distributions of employment and wages that constitute an equilibrium of the model.

Definition 2. Given parameter values $\Theta$ and fundamentals $\left\{\boldsymbol{H}, \boldsymbol{B}(\boldsymbol{\Theta}), \boldsymbol{K}_{c}^{\prime}(\boldsymbol{\Theta}), \mathcal{E}, \boldsymbol{\tau}(\psi)\right\}$, the post-shock equilibrium is characterized by $\left\{\boldsymbol{L}_{c}^{\prime}(\boldsymbol{\Theta}), \boldsymbol{W}_{c}^{\prime}(\boldsymbol{\Theta}), \boldsymbol{l}_{c}^{\prime}(\boldsymbol{\Theta}), \boldsymbol{w}_{c}^{\prime}(\boldsymbol{\Theta})\right\}$.

The prime superscript denotes variables that are affected by the MDP openings, and $c$ denotes "cases," consistent with our reduced-form analysis.

Proposition 1 states that, under certain parametric restrictions, the post-shock equilibrium is unique up to a normalization. It is easy to verify that these restrictions hold under the calibrated parameter values. Proposition 2 states that we can recover unique values of the unobserved fundamentals and plant-level distributions of employment and wages that rationalize the data as an equilibrium of the model. Together, these two uniqueness results imply that our counterfactuals yield determinate predictions.

\subsection{Estimation}

Using the micro-level data set, we run plant-level difference-in-differences regressions that mirror those in our reduced-form analysis. This yields model-based estimates $\boldsymbol{m}(\boldsymbol{\Theta})$ that constitute the counterparts of our reduced-form estimates $\boldsymbol{m}$. Given the estimates, the parameter vector estimate $\hat{\Theta}$ minimizes the loss function $(\boldsymbol{m}-\boldsymbol{m}(\Theta))^{\prime} \boldsymbol{G}(\boldsymbol{m}-\boldsymbol{m}(\Theta))$, 
where $G$ is a positive definite weighting matrix set equal to the inverse of the sample variance-covariance matrix of the data moments.

Panel A of Table 8 presents the estimation results. ${ }^{27}$ The parameter $\kappa$ measures the semi-elasticity of knowledge in the winner county to the MDP openings. The estimated value of 0.039 implies an increase in local knowledge which, in conjunction with the (calibrated) elasticity of local productivity to agglomeration $\beta$, allows us to perfectly match the local productivity response in the winner county. The parameter $\theta$ controls the magnitude of the global productivity spillover. The estimated value of 0.94 implies a significant degree of knowledge sharing across plants within firm boundaries, generating productivity spillovers that are consistent with our reduced-form estimates. Finally, the parameters $\rho$ and $v$ control within-location labor supply and demand, respectively. Together, they determine the wage and employment responses to the global productivity spillover. As for $\rho$, the estimated value of 0.61 implies within-location labor supply is highly elastic, albeit not perfectly elastic, generating meaningful within-location wage heterogeneity. As for $v$, the estimated value of 0.013 implies a relatively high degree of specialization across plants within a given location, implying a muted response of labor demand to productivity changes.

Panel B compares the model-based estimates with their reduced-form counterparts. We target four central moments which, as discussed above, are tightly linked to the four parameters of interest: the local productivity spillover estimate (linked to $\kappa$ ), the global productivity spillover estimate (linked to $\theta$ ), and the global employment and wage spillover estimates (linked to $\rho$ and $v$ ). As is shown, our model exactly matches all four moments, affirming the close link between structural parameters and economic forces in our model. We note that our model also matches the other two spillover estimates well; it (almost) exactly matches the local employment spillover estimate, and our estimate of the local wage spillover lies comfortably within one standard error of the reduced-form estimate.

\section{Counterfactuals}

Given our parameter estimates, we can undertake counterfactuals to quantify the significance of knowledge sharing through plant-level networks for the distribution of economic activity, as well as for the propagation and amplification of local productivity shocks. We first consider the effects of an increase in within-firm, across-location

\footnotetext{
${ }^{27}$ Standard errors are calculated using conventional asymptotic theory. The sample variance-covariance matrix is estimated via influence functions (Hampel, 2011); the Jacobian of the objective function is calculated using numerical differentiation.
} 
knowledge sharing on the distribution of economic activity. Subsequently, we consider the general equilibrium effects of local productivity shocks, such as those arising from place-based policies, with and without knowledge sharing between plants.

\subsection{Distributional Effects of Knowledge Sharing}

In our model, the strength of within-firm, across-location knowledge sharing is governed by the structural parameter $\theta$. Holding all (other) parameters and fundamentals fixed, we counterfactually increase $\theta$ by $1 \%$ and solve for the (new) county- and plant-level distributions of employment and wages that constitute an equilibrium of our model. Intuitively, an increase in $\theta$ makes $\mathrm{MC}$ plants more productive. Given a reduction in marginal costs, MC plants increase labor demand, pushing up nominal wages, but not enough to offset the reduction in marginal costs. As a result, goods prices decline, which pushes up real wages. In equilibrium, counties with more $\mathrm{MC}$ plants experience relatively large average real wage increases, as well as labor inflows, while counties with fewer MC plants experience smaller average real wage increases and labor outflows. ${ }^{28}$

Figure 2 shows the distributional effects of an increase in $\theta$. Counties are sorted into percentiles based on their population in 1987 Census data. As can be seen, the county-level population distribution is strongly skewed; the $10 \%$ most populous counties have a population share of about $63 \%$. Importantly, as shown in Figure 1, these counties have about $60 \%$ of all MC plants. Hence, the productivity gains from an increase in $\theta$ are disproportionately concentrated in the most populous counties. As Figure 2 shows, these counties experience large average real wage gains, as well as labor inflows, while less populous counties experience smaller average real wage gains and labor outflows. The combined effect-i.e., combining changes in real wages and labor flows-is that the most populous counties experience large gains in real GDP, while less populous counties experience real GDP losses. ${ }^{29}$ Note that more populous counties also exhibit higher levels of real GDP; the correlation between population and real GDP at the county level in 1987 is $92 \%$. Accordingly, an increase in the strength of within-firm, across-location knowledge sharing widens economic disparities between regions: those with high real GDP become richer, and those with low real GDP become poorer.

\footnotetext{
${ }^{28}$ While labor inflows (outflows) cause land prices to increase (decrease), this does not fully offset the nominal wage and goods price effects.

${ }^{29}$ In our model, county-level real GDP is $\frac{W_{n} L_{n}}{P_{n}^{\alpha} R_{n}^{1-\alpha}}$. Hence, for real GDP to decline in less populous counties, the (percent) gain in average real wages must be less than the (percent) decrease in county-level employment.
} 


\subsection{Knowledge Sharing and Local Productivity Shocks}

Our reduced-form analysis shows significant spillover effects of local productivity shocks; treated plants in distant counties experience large increases in productivity and employment. While informative, inferences drawn from our reduced-form analysis are limited, for two reasons. For one, without a suitable empirical proxy for utility, it cannot speak to the welfare implications of local productivity shocks. Second, since all plants in the economy are affected through general equilibrium effects (labor flows, goods trade), non-treated plants in distant counties provide an imperfect counterfactual to quantify the significance of knowledge sharing for the amplification of local productivity shocks. For example, as (manufacturing) goods are tradable, changes in goods prices affect real wages across all plants in the economy, including non-treated plants.

Our second counterfactual addresses both of these issues. We measure changes in worker-level utility resulting from local productivity shocks, such as those arising from place-based policies, with and without knowledge sharing between plants. In the scenario with knowledge sharing, we implement Steps 1 and 2 of Section 4.3 using the estimated parameter values. In the scenario without knowledge sharing, we do the same, except we counterfactually set $\theta=0 .{ }^{30}$ In both cases, we simulate productivity shocks at the state level by increasing log local knowledge $K_{i}$ in the state by $\kappa \cdot{ }^{31}$ Together with classical agglomeration forces, this implies state-level productivity increases by $4 \%$. We independently shock all 50 U.S. states and report averages across the 50 experiments.

\subsubsection{Aggregate Welfare}

We first quantify by how much knowledge sharing amplifies the aggregate welfare effects of local productivity shocks. Aggregate welfare is computed as in equation (15). Without knowledge sharing, a $4 \%$ state-level productivity shock generates, on average, a $0.083 \%$ increase in aggregate productivity and a corresponding $0.053 \%$ increase in aggregate welfare. With knowledge sharing, aggregate productivity increases by $0.15 \%$, while aggregate welfare increases by $0.087 \%$. Thus, knowledge sharing through plant-level networks significantly amplifies the welfare gains from local productivity shocks.

\subsubsection{Worker-Level Heterogeneity}

We next explore heterogeneity in worker-level utility changes from local productivity shocks. In models with labor mobility and Fréchet-distributed idiosyncratic preferences

\footnotetext{
${ }^{30}$ If $\theta=0$, our model admits a representative plant in each location, similar to a standard Armington model.

${ }^{31}$ Simulating county-level productivity shocks yield similar results, except the welfare gains are smaller.
} 
over locations, changes in average utility are equalized across locations. However, utility changes are not (generically) equalized across individuals. To explore heterogeneity in utility changes at the individual level, we compare workers based on their ex-ante (i.e., pre-shock) location and plant choices. ${ }^{32}$ Specifically, we compare the utility changes of i) workers who ex-ante live in the state with the productivity shock, ii) workers who ex-ante live in another state working for a plant that is connected to the shocked state (through the firm's plant-level network), and iii) workers who ex-ante live in another state working for a plant that is not connected to the shocked state.

Table 9 presents the results. Without knowledge sharing, only plants in the shocked state become more productive. Workers in that state experience utility gains of $1.19 \%$, driven by wage increases and falling prices of goods produced in the state (and only partly offset by rising land prices). Worker in other states also benefit from the fall in goods prices, albeit much less due to the gravity relationship in goods trade. Their utility increases by $0.029 \%$ (non-connected plants) and $0.028 \%$ (connected plants), respectively. Thus, without knowledge sharing between plants, workers in other states benefit similarly from the productivity shock, regardless of which type of plant they work for.

With knowledge sharing, some plants in other states also become more productive. Workers in the state with the productivity shock experience utility gains of $1.22 \%$, which is only slightly higher than before. For those workers, the wage and price effects in their own state remain the driving force behind their utility gains. In contrast, for workers in other states, the utility gains are now much higher than before. As some plants in those states become more productive, goods produced in those states become cheaper, which mainly benefits workers in (or near) those states due to the gravity relationship in goods trade. As a result, workers at non-connected plants now experience utility gains of $0.056 \%$, which is almost twice as large as before. Crucially, workers at connected plants experience utility gains of $0.30 \%$, which is ten times larger than before. Those workers benefit from nominal wage increases, in addition to falling goods prices, as their plants have become more productive. Hence, while knowledge sharing between plants benefits all workers, it especially benefits workers in other states working at connected plants.

\footnotetext{
${ }^{32}$ Equalization of changes in average utility across locations is based on comparing the utilities of workers who ex-post live in a location with the utilities of workers who ex-ante live in the location. Thus, if there is either in- or out-migration, equalization of changes in average utility is based on comparing different sets of workers. By contrast, we hold individual workers fixed and compare their utilities before and after the shock.
} 


\subsubsection{Region-Level Heterogeneity}

To explore the regional implications of the worker-level heterogeneity, we average changes in worker-level utility at the county level based on workers' ex-ante location choices. In Figure 3, counties are sorted into percentiles based on their population in 1987. As can be seen, without knowledge sharing, all counties benefit similarly from a state-level productivity shock; the distribution of average utility gains is effectively flat. With knowledge sharing, the entire distribution is shifted upward. Importantly, it is highly skewed; the most populous counties, which have the most connected plants, exhibit by far the largest average utility gains. Hence, knowledge sharing between plants leads to a highly uneven distribution of the welfare gains from local productivity shocks.

\section{Conclusion}

We provide both reduced-form and model-based evidence that local productivity spillovers propagate throughout the economy through the plant-level networks of multi-region firms. In our reduced-form setting, we show that large manufacturing plant openings not only raise the productivity of local incumbent plants but also of distant plants hundreds of miles away, which belong to multi-region firms that are exposed to the local productivity spillover through one of their plants. This "global" productivity spillover does not decay with geographical distance and is stronger in (knowledge-based) industries characterized by mutual R\&D flows and patent citations.

To quantify the significance of plant-level networks for the propagation and amplification of local productivity shocks, we develop and estimate a quantitative spatial model with goods trade, labor mobility, plant-level networks, and a rich geography, where plants of the same firm, across regions, are linked through shared knowledge. Counterfactuals show that knowledge sharing between plants widens disparities across regions; those with high real GDP become richer, whereas those with low real GDP become poorer. Moreover, while knowledge sharing amplifies the aggregate effects of local productivity shocks, it leads to a highly uneven distribution of the welfare gains-highly populous regions, which tend to be more connected (through plant-level networks) to the region with the productivity shock, experience by far the largest average utility gains. 


\section{References}

Acemoglu, Daron, Vasco Carvalho, Asuman Ozdaglar, and Alireza Tahbaz-Salehi, 2012, The Network Origins of Aggregate Fluctuations, Econometrica 80, 1977-2016.

Acemoglu, Daron, and Alireza Tahbaz-Salehi, 2020, Firms, Failures, and Fluctuations: The Macroeconomics of Supply Chain Disruptions, mimeo, MIT.

Ahlfeldt, Gabriel, Stephen Redding, Daniel Sturm, and Nikolaus Wolf, 2015, The Economics of Density: Evidence from the Berlin Wall, Econometrica 83, 2127-2189.

Allen, Treb, and Costas Arkolakis, 2014, Trade and the Topography of the Spatial Economy, Quarterly Journal of Economics 129, 1085-1140.

Allen, Treb, Costas Arkolakis, and Xiangliang Li, 2020, On the Equilibrium Properties of Network Models with Heterogeneous Agents, mimeo, Dartmouth College.

Anderson, James, 1979, A Theoretical Foundation for the Gravity Equation, American Economic Review 69, 106-116.

Arkolakis, Costas, Svetlana Demidova, Peter Klenow, and Andrés Rodríguez-Clare, 2008, Endogenous Variety and the Gains from Trade, American Economic Review Papers \& Proceedings 98, 444-450.

Armington, Paul, 1969, A Theory of Demand for Products Distinguished by Place of Production, IMF Staff Papers 16, 159-178.

Barrot, Jean-Noël, and Julien Sauvagnat, 2016, Input Specificity and the Propagation of Idiosyncratic Shocks in Production Networks, Quarterly Journal of Economics 131, 1543-1592.

Bartelme, Dominick, Arnaud Costinot, Dave Donaldson, and Andrés Rodríguez-Clare, 2019, The Textbook Case for Industrial Policy: Theory Meets Data, mimeo, University of Michigan.

Bartik, Timothy, 2020, Using Place-Based Jobs Policies to Help Distressed Communities, Journal of Economic Perspectives 34, 99-127.

Bernard, Andrew, Jonathan Eaton, Bradford Jensen, and Samuel Kortum, 2003, Plants and Productivity in International Trade, American Economic Review 93, 1268-1290.

Bilir, Kamran, and Eduardo Morales, 2020, Innovation in the Global Firm, Journal of Political Economy 128, 1566-1625.

Broda, Christian, and David Weinstein, 2006, Globalization and the Gains from Variety, Quarterly Journal of Economics 121, 541-585.

Bryan, Gharad, and Melanie Morten, 2019, The Aggregate Productivity Effects of Internal Migration: Evidence from Indonesia, Journal of Political Economy 127, 2229-2268.

Buera, Francisco, and Robert Lucas, 2018, Idea Flows and Economic Growth, Annual Review of Economics 10, 315-345. 
Busso, Matias, Jesse Gregory, and Patrick Kline, 2013, Assessing the Incidence and Efficiency of a Prominent Place Based Policy, American Economic Review 103, 897-947.

Caliendo, Lorenzo, and Esteban Rossi-Hansberg, 2012, The Impact of Trade on Organization and Productivity, Quarterly Journal of Economics 127, 1393-1467.

Caliendo, Lorenzo, Ferdinando Monte, and Esteban Rossi-Hansberg, 2015, The Anatomy of French Production Hierarchies, Journal of Political Economy 123, 809-852.

Caliendo, Lorenzo, Fernando Parro, Esteban Rossi-Hansberg, and Pierre-Daniel Sarte, 2018, The Impact of Regional and Sectoral Productivity Changes on the U.S. Economy, Review of Economic Studies 85, 2042-2096.

Carvalho, Vasco, Makoto Nirei, Yukiko Saito, and Alireza Tahbaz-Salehi, 2020, Supply Chain Disruptions: Evidence from the Great East Japan Earthquake, Quarterly Journal of Economics, forthcoming.

Chaney, Thomas, 2008, Distorted Gravity: The Intensive and Extensive Margins of International Trade, American Economic Review 98, 1707-1721.

Combes, Pierre-Philippe, and Laurent Gobillon, 2015, The Empirics of Agglomeration Economies, in: Handbook of Regional and Urban Economics, Volume 5A, Gilles Duranton, Vernon Henderson, and William Strange (eds.). Amsterdam: North-Holland.

Davis, Morris, and François Ortalo-Magné, 2011, Household Expenditures, Wages, Rents, Review of Economic Dynamics 14, 248-261.

Eaton, Jonathan, and Samuel Kortum, 2002, Technology, Geography, and Trade, Econometrica 70, 1741-1779.

Eaton, Jonathan, Samuel Kortum, and Sebastian Sotelo, 2012, International Trade: Linking Micro and Macro, NBER Working Paper 17864.

Ellison, Glenn, Edward Glaeser, and William Kerr, 2010, What Causes Industry Agglomeration? Evidence from Coagglomeration Patterns, American Economic Review 100, 1195-1213.

Fajgelbaum, Pablo, and Cecile Gaubert, 2020, Optimal Spatial Policies, Geography, and Sorting, Quarterly Journal of Economics 135, 959-1036.

Gabaix, Xavier, 2011, The Granular Origins of Aggregate Fluctuations, Econometrica 79, 733-772.

Gaubert, Cecile, 2018, Firm Sorting and Agglomeration, American Economic Review 108, 3117-3153.

Gaubert, Cecile, and Oleg Itskhoki, 2021, Granular Competitive Advantage, Journal of Political Economy 129, 871-939. 
Gaubert, Cecile, Patrick Kline, and Danny Yagan, 2020, Place-Based Redistribution, mimeo, UC Berkeley.

Giroud, Xavier, and Holger Mueller, 2019, Firms' Internal Networks and Local Economic Shocks, American Economic Review 109, 3617-3649.

Glaeser, Edward, and Joshua Gottlieb, 2008, The Economics of Place-Making Policies, Brookings Papers on Economic Activity, Spring, 155-239.

Greenstone, Michael, and Enrico Moretti, 2003, Bidding for Industrial Plants: Does Winning a 'Million Dollar Plant' Increase Welfare? NBER Working Paper 9844.

Greenstone, Michael, Richard Hornbeck, and Enrico Moretti, 2010, Identifying Agglomeration Spillovers: Evidence from Winners and Losers of Large Plant Openings, Journal of Political Economy 118, 536-598.

Hampel, Frank, Elvezio Ronchetti, Peter Rousseeuw, and Werner Stahel, 2011. Robust Statistics: The Approach Based on Influence Functions. New York: John Wiley \& Sons.

Hornbeck, Richard, and Enrico Moretti, 2020, Estimating Who Benefits From Productivity Growth: Local and Distant Effects of City TFP Shocks on Wages, Rents, and Inequality, mimeo, University of Chicago.

Kline, Patrick, and Enrico Moretti, 2014a, People, Places, and Public Policy: Some Simple Welfare Economics of Local Economic Development Programs, Annual Review of Economics 6, 629-662.

Kline, Patrick, and Enrico Moretti, 2014b, Local Economic Development, Agglomeration Economies, and the Big Push: 100 Years of Evidence from the Tennessee Valley Authority, Quarterly Journal of Economics 129, 275-331.

Krugman, Paul, 1980, Scale Economies, Product Differentiation, and the Pattern of Trade, American Economic Review 70, 950-959.

Lind, Nelson, and Natalia Ramondo, 2021, Trade with Correlation, mimeo, Emory University.

Long, John, and Charles Plosser, 1983, Real Business Cycles, Journal of Political Economy 91, 39-69.

Lucas, Robert, and Benjamin Moll, 2014, Knowledge Growth and the Allocation of Time, Journal of Political Economy 122, 1-51.

Markusen, James, 1984, Multinationals, Multi-Plant Economies, and the Gains from Trade, Journal of International Economics 16, 205-226.

Marshall, Alfred, 1890. Principles of Economics. London: Macmillan.

McFadden, Daniel, 1978, Modelling the Choice of Residential Location, in: Spatial Interaction Theory and Planning Models, Anders Karlqvist, Lars Lundqvist, Folke Snickars, and Jörgen Weibull (eds.). Amsterdam: North-Holland. 
Melitz, Mark, 2003, The Impact of Trade on Intra-Industry Reallocations and Aggregate Industry Productivity, Econometrica 71, 1695-1725.

Monte, Ferdinando, Stephen Redding, and Esteban Rossi-Hansberg, 2018, Commuting, Migration, and Local Employment Elasticities, American Economic Review 108, 3855-3890.

Moretti, Enrico, 2010, Local Labor Markets, in: Handbook of Labor Economics, Volume 4B, Orley Ashenfelter and David Card (eds.). Amsterdam: North-Holland.

Neumark, David, and Helen Simpson, 2015, Place-Based Policies, in: Handbook of Regional and Urban Economics, Volume 5B, Gilles Duranton, Vernon Henderson, and William Strange (eds.). Amsterdam: North-Holland.

Perla, Jesse, and Christopher Tonetti, 2014, Equilibrium Imitation and Growth, Journal of Political Economy 122, 52-76.

Redding, Stephen, 2016, Goods Trade, Factor Mobility and Welfare, Journal of International Economics 101, 148-167.

Redding, Stephen, and Esteban Rossi-Hansberg, 2017, Quantitative Spatial Economics, Annual Review of Economics 9, 21-58.

Rosenthal, Stuart, and William Strange, 2004, Evidence on the Nature and Sources of Agglomeration Economies, in: Handbook of Regional and Urban Economics, Volume 4, Vernon Henderson and Jacques-François Thisse (eds.). Amsterdam: North-Holland.

Rosenthal, Stuart, and William Strange, 2020, How Close Is Close? The Spatial Reach of Agglomeration Economies, Journal of Economic Perspectives 34, 27-49.

Rossi-Hansberg, Esteban, Pierre-Daniel Sarte, and Felipe Schwartzman, 2020, Cognitive Hubs and Spatial Redistribution, mimeo, Princeton University.

Story, Louise, 2012, As Companies Seek Tax Deals, Governments Pay High Price, New York Times, December 1. 


\section{Figure 1: Spatial Allocation of MC Plants}

This figure shows the distribution of MC plants across counties. Counties are sorted into deciles based on their population in 1987 Census data. The gray bars depict the share of MC plants, relative to all MC plants in the economy, associated with a given decile in the 1987 CMF. The blue bars depict the corresponding shares in the model.

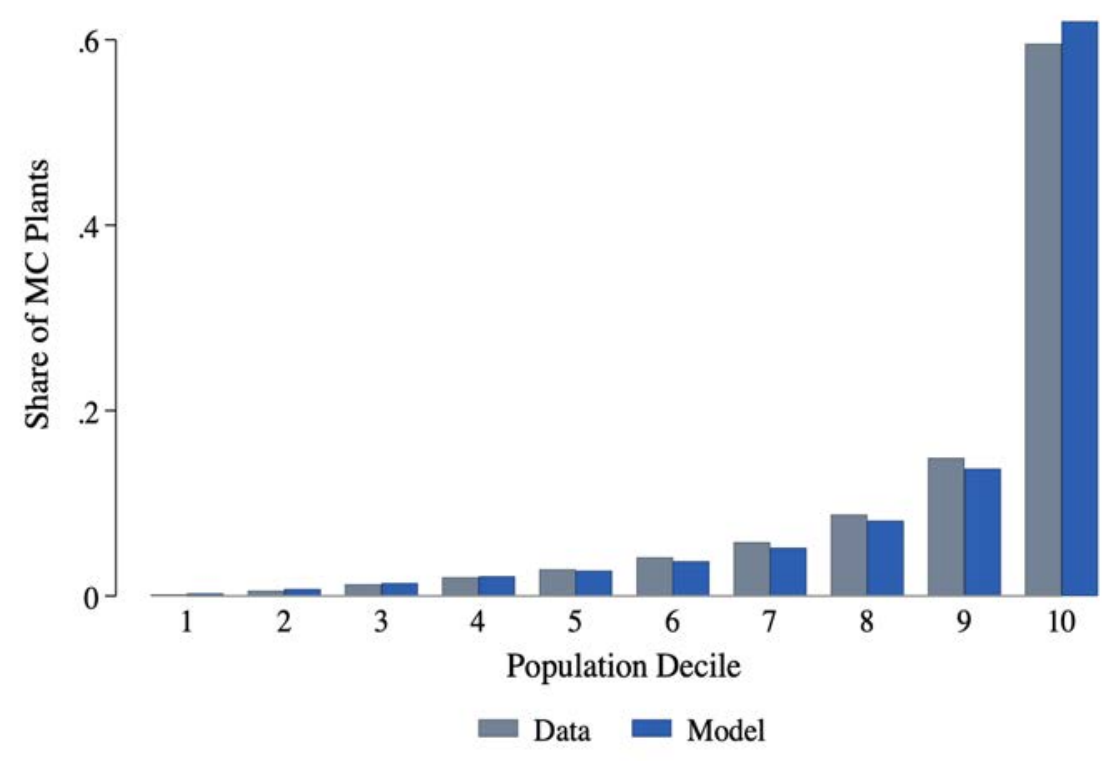




\section{Figure 2: Increase in Knowledge Sharing}

This figure shows changes in average real wages and employment at the county level from a $1 \%$ increase in $\theta$. Counties are sorted into percentiles based on their population in 1987 Census data.

Panel A: Changes in average real wages

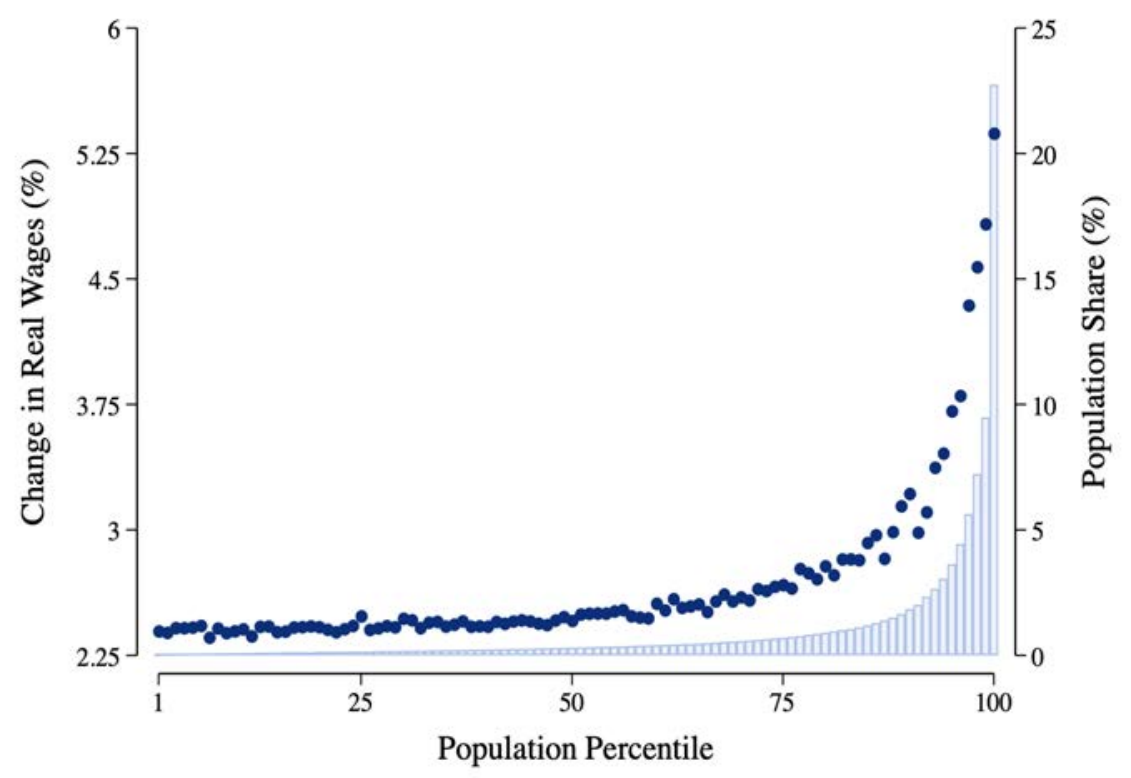

Panel B: Changes in employment

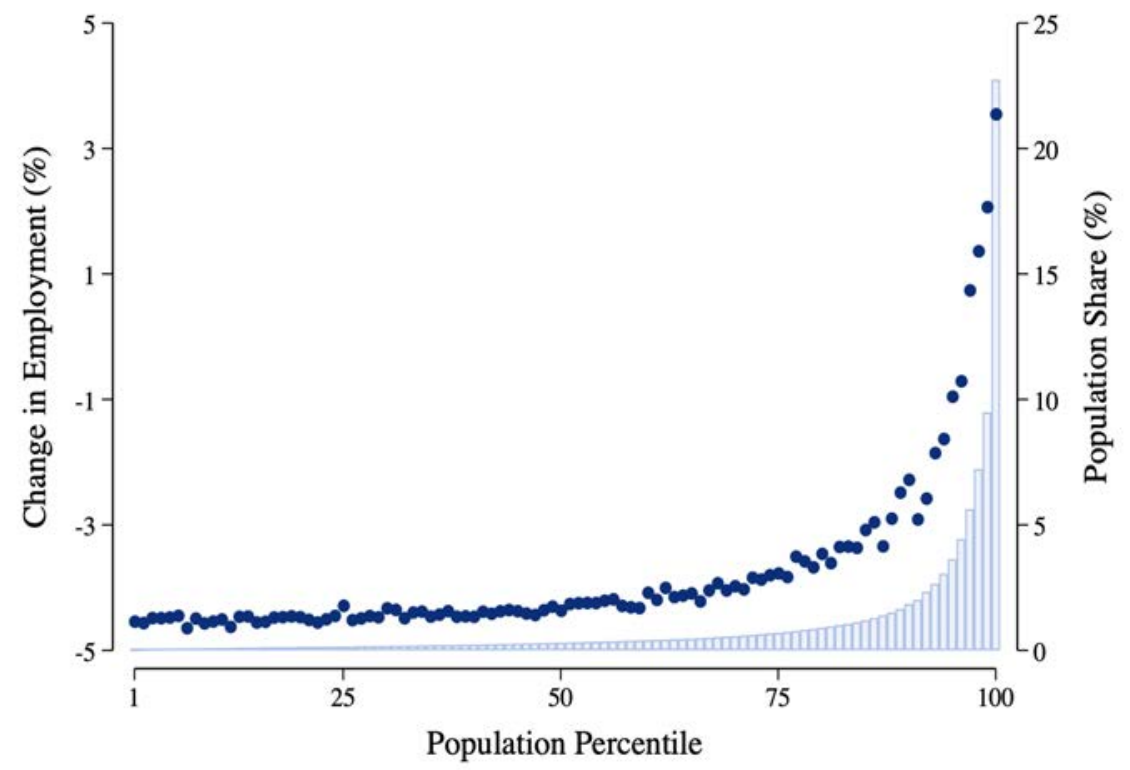




\section{Figure 3: Propagation and Amplification of Local Productivity Shocks}

This figure shows changes in average worker-level utility at the county level from a $4 \%$ increase in productivity in one state. All 50 states are independently shocked; the figure shows averages across all 50 experiments. Counties are sorted into percentiles based on their population in 1987 Census data. Panel A considers an economy without knowledge sharing between plants. Panel B considers an economy with knowledge sharing between plants.

Panel A: Without knowledge sharing

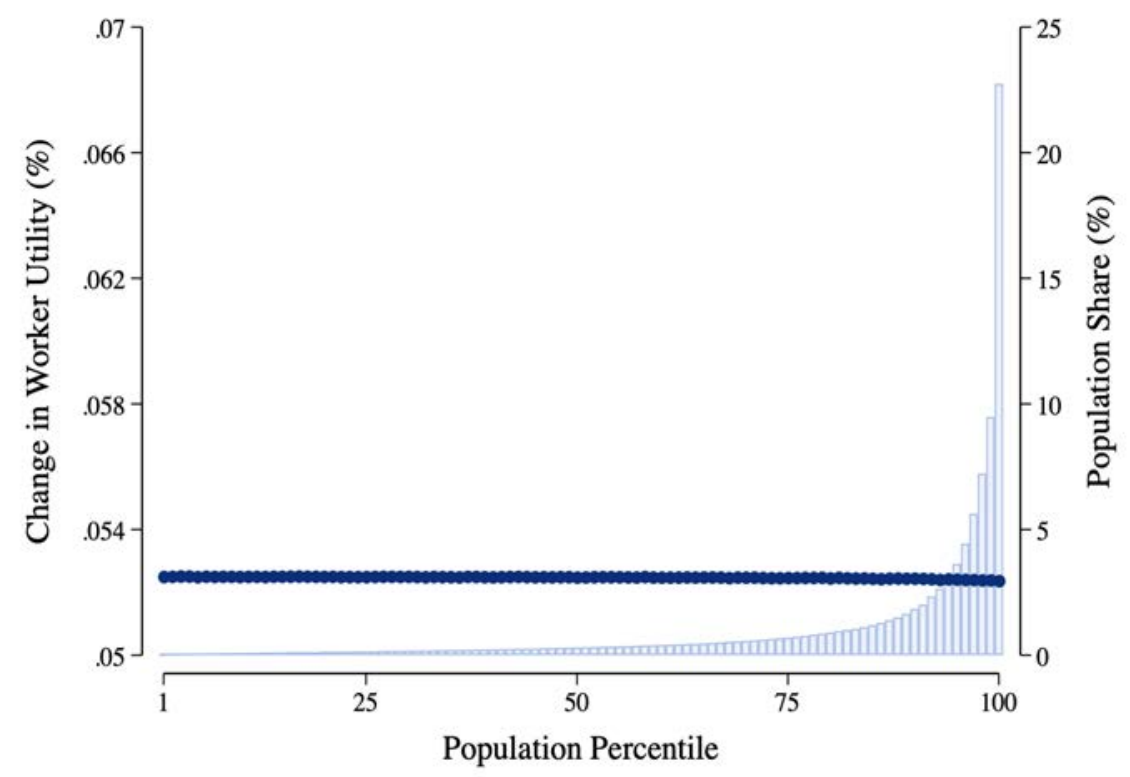

Panel B: With knowledge sharing

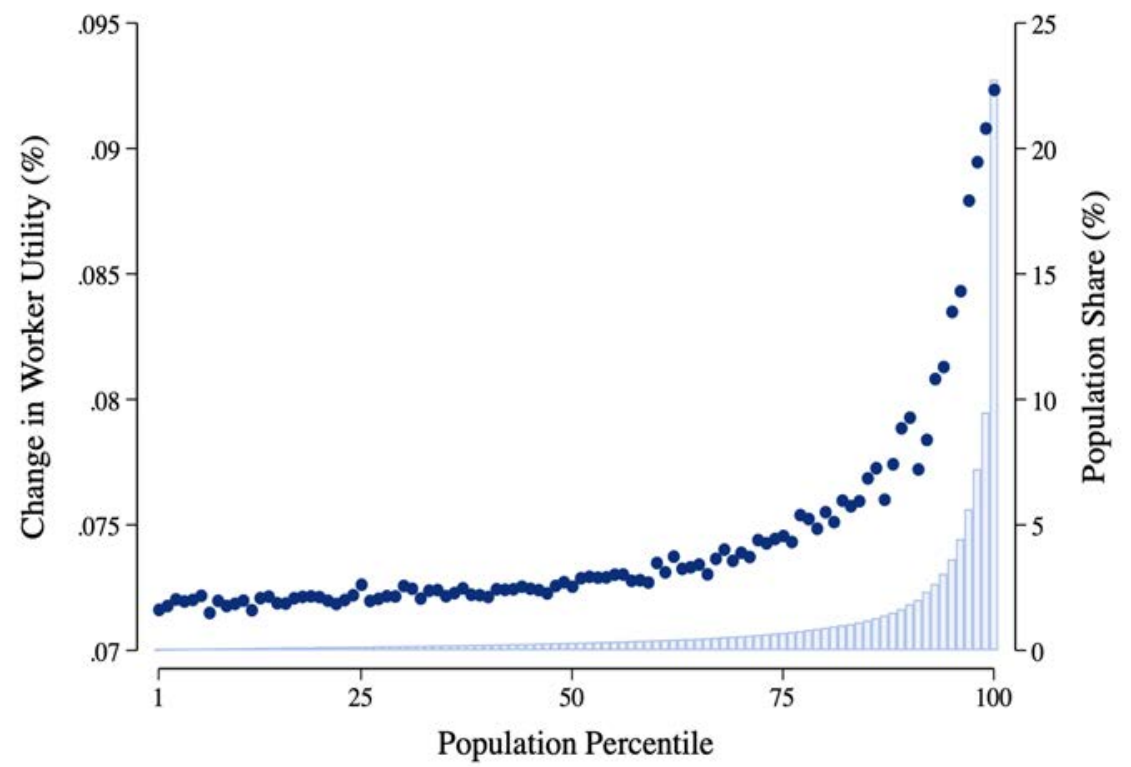




\section{Table 1: Descriptive Statistics}

Panel A provides plant-level statistics for the local spillover sample consisting of 157,400 plant-year observations. Panel B provides plant-level statistics for the global spillover sample consisting of 422,500 plant-year observations. Panel C provides firm-level statistics for the parent firms associated with the plants in Panel B. Column (4) reports $p$-values of the difference between columns (2) and (3). Wages are in $\$ 1,000$. All statistics are from the year before the MDP opening. Standard deviations are in parentheses. The sample period is from 1977 to 1998.

\begin{tabular}{|c|c|c|c|c|}
\hline & (1) & (2) & (3) & (4) \\
\hline Panel A: & All & Winner & Loser & $\begin{array}{c}p \text {-value } \\
(2)-(3)\end{array}$ \\
\hline Employees & $\begin{array}{c}141.7 \\
(571.4)\end{array}$ & $\begin{array}{c}146.3 \\
(589.3)\end{array}$ & $\begin{array}{c}139.8 \\
(562.8)\end{array}$ & 0.377 \\
\hline Wages & $\begin{array}{c}39.5 \\
(852.7)\end{array}$ & $\begin{array}{c}41.5 \\
(877.2)\end{array}$ & $\begin{array}{c}38.7 \\
(763.9)\end{array}$ & 0.454 \\
\hline TFP & $\begin{array}{c}0.002 \\
(0.586)\end{array}$ & $\begin{array}{c}0.003 \\
(0.610)\end{array}$ & $\begin{array}{c}0.001 \\
(0.551)\end{array}$ & 0.672 \\
\hline Panel B: & All & Treated & Control & $\begin{array}{c}p \text {-value } \\
(2)-(3)\end{array}$ \\
\hline Employees & $\begin{array}{c}268.2 \\
(846.7)\end{array}$ & $\begin{array}{c}272.6 \\
(903.4)\end{array}$ & $\begin{array}{c}266.3 \\
(821.8)\end{array}$ & 0.482 \\
\hline Wages & $\begin{array}{c}35.9 \\
(202.2)\end{array}$ & $\begin{array}{c}34.3 \\
(311.5)\end{array}$ & $\begin{array}{c}36.5 \\
(162.9)\end{array}$ & 0.535 \\
\hline TFP & $\begin{array}{c}0.016 \\
(0.640)\end{array}$ & $\begin{array}{c}0.017 \\
(0.653)\end{array}$ & $\begin{array}{c}0.016 \\
(0.637)\end{array}$ & 0.903 \\
\hline Panel C: & All & Treated & Control & $\begin{array}{c}p \text {-value } \\
(2)-(3)\end{array}$ \\
\hline Employees & $\begin{array}{c}1,988 \\
(6,702)\end{array}$ & $\begin{array}{c}1,968 \\
(6,862)\end{array}$ & $\begin{array}{c}1,997 \\
(6,548)\end{array}$ & 0.834 \\
\hline Plants & $\begin{array}{c}7.4 \\
(10.9)\end{array}$ & $\begin{array}{c}7.3 \\
(10.6)\end{array}$ & $\begin{array}{c}7.5 \\
(11.0)\end{array}$ & 0.661 \\
\hline Counties & $\begin{array}{c}5.4 \\
(7.7)\end{array}$ & $\begin{array}{c}5.3 \\
(7.2)\end{array}$ & $\begin{array}{c}5.5 \\
(7.8)\end{array}$ & 0.532 \\
\hline States & $\begin{array}{c}2.7 \\
(2.8)\end{array}$ & $\begin{array}{c}2.6 \\
(2.6)\end{array}$ & $\begin{array}{c}2.8 \\
(2.9)\end{array}$ & 0.448 \\
\hline
\end{tabular}




\section{Table 2: Local Productivity Spillover}

The dependent variable is TFP at the plant level. MDP is an indicator for the winner county that is one from the year of the MDP opening onward. In column (2), (<50 miles), (50 to 100 miles), and (100 to 250 miles) are indicators for whether a plant lies within 50 miles, between 50 and 100 miles, and between 100 and 250 miles, respectively, of the MDP. Observations are weighted by plant-level employment. Standard errors are double clustered at the county and year level. The sample period is from 1977 to $1998 .{ }^{*},{ }^{* *}$, and ${ }^{* * *}$ denotes significance at the $10 \%, 5 \%$, and $1 \%$ level, respectively.

\begin{tabular}{lcc}
\hline & \multicolumn{2}{c}{ TFP } \\
\cline { 2 - 3 } & $(1)$ & $(2)$ \\
\cline { 2 - 3 } MDP & $0.040^{* *}$ & \\
MDP $\times(<50$ miles $)$ & $(0.016)$ & \\
& & $0.043^{* * *}$ \\
MDP $\times(50$ to 100 miles $)$ & & $(0.015)$ \\
& & $0.027^{*}$ \\
MDP $\times(>100$ miles $)$ & & $(0.014)$ \\
& & 0.011 \\
Plant FE & & $(0.010)$ \\
Industry $\times$ year FE & Yes & Yes \\
Case FE & Yes & Yes \\
R-squared & Yes & Yes \\
Observations & 0.88 & 0.86 \\
& 157,000 & $2,209,000$ \\
\hline
\end{tabular}




\section{Table 3: Global Productivity Spillover}

The dependent variable is TFP at the plant level. MDP is an indicator for whether the plant's parent firm has a plant in the winner county before and after the MDP opening. The indicator is one from the year of the MDP opening onward. All samples are restricted to plants of MC firms outside the winner or runner-up counties. Observations are weighted by plant-level employment. Standard errors are double clustered at the county and year level. The sample period is from 1977 to 1998. *, **, and ${ }^{* * *}$ denotes significance at the $10 \%, 5 \%$, and $1 \%$ level, respectively.

\begin{tabular}{lccc}
\hline & \multicolumn{3}{c}{ TFP } \\
\cline { 2 - 4 } & $(1)$ & $(2)$ & $(3)$ \\
\cline { 2 - 4 } MDP & $0.018^{* *}$ & $0.020^{* *}$ & $0.018^{* *}$ \\
& $(0.007)$ & $(0.008)$ & $(0.008)$ \\
Plant FE & Yes & Yes & Yes \\
Industry $\times$ county $\times$ year FE & No & Yes & Yes \\
Industry $\times$ year FE & Yes & - & - \\
Case FE & Yes & - & Yes \\
Countrol group & Plants of & Plants of & Plants of \\
& runner-up firms & MC firms & runner-up firms \\
R-squared & & in same county & in same county \\
Observations & 0.87 & 0.86 & 0.88 \\
\hline
\end{tabular}




\section{Table 4: Distance to MDP}

This table presents variants of the regression in column (3) of Table 3 in which treated plants in close proximity to the MDP are excluded from the sample. Observations are weighted by plant-level employment. Standard errors are double clustered at the county and year level. The sample period is from 1977 to $1998 .{ }^{*},{ }^{* *}$, and ${ }^{* * *}$ denotes significance at the $10 \%, 5 \%$, and $1 \%$ level, respectively.

\begin{tabular}{|c|c|c|c|c|c|}
\hline & \multicolumn{5}{|c|}{ TFP } \\
\hline & $\begin{array}{c}\text { Excluding plants } \\
\text { within } 100 \\
\text { miles of MDP }\end{array}$ & $\begin{array}{c}\text { Excluding plants } \\
\text { within } 250 \\
\text { miles of MDP }\end{array}$ & $\begin{array}{c}\text { Excluding plants } \\
\text { within } 500 \\
\text { miles of MDP }\end{array}$ & $\begin{array}{l}\text { Excluding plants } \\
\text { in MDP state }\end{array}$ & $\begin{array}{c}\text { Excluding plants } \\
\text { in MDP Census } \\
\text { division }\end{array}$ \\
\hline & $(1)$ & $(2)$ & (3) & (4) & $(5)$ \\
\hline MDP & $\begin{array}{l}0.018^{* *} \\
(0.007)\end{array}$ & $\begin{array}{l}0.017^{* *} \\
(0.007)\end{array}$ & $\begin{array}{l}0.018^{* *} \\
(0.008)\end{array}$ & $\begin{array}{l}0.018^{* *} \\
(0.008)\end{array}$ & $\begin{array}{l}0.018^{* *} \\
(0.008)\end{array}$ \\
\hline Plant FE & Yes & Yes & Yes & Yes & Yes \\
\hline Industry $\times$ county $\times$ year FE & Yes & Yes & Yes & Yes & Yes \\
\hline Case FE & Yes & Yes & Yes & Yes & Yes \\
\hline R-squared & 0.88 & 0.88 & 0.89 & 0.88 & 0.88 \\
\hline Observations & 402,000 & 365,000 & 286,000 & 395,000 & 345,000 \\
\hline
\end{tabular}


Table 5: Industries, R\&D Flows, and Patent Citations

This table presents variants of the regression in column (3) of Table 3. In columns (1) and (2), both terms in equation (1) are interacted with a dummy variable indicating whether the treated plant is in the same 4-digit SIC code industry as eiher the firm's plant in the winner county ("winner plant") or the MDP. In columns (3) to (6), both terms in equation (1) are interacted with measures of either mutual R\&D flows or mutual patent citations between the industry of the treated plant and either the industry of the firm's plant in the winner county or the industry of the MDP. Observations are weighted by plant-level employment. Standard errors are double clustered at the county and year level. The sample period is from 1977 to $1998 .{ }^{*},{ }^{* *}$, and ${ }^{* * *}$ denotes significance at the $10 \%, 5 \%$, and $1 \%$ level, respectively.

\begin{tabular}{|c|c|c|c|c|c|c|}
\hline & \multicolumn{6}{|c|}{ TFP } \\
\hline & \multicolumn{2}{|c|}{ Same industry } & \multicolumn{2}{|c|}{ Mutual R\&D flows } & \multicolumn{2}{|c|}{ Mutual patent citations } \\
\hline & $(1)$ & $(2)$ & (3) & $(4)$ & $(5)$ & (6) \\
\hline MDP & $\begin{array}{l}0.017^{* *} \\
(0.008)\end{array}$ & $\begin{array}{l}0.017^{* *} \\
(0.008)\end{array}$ & $\begin{array}{l}0.014^{*} \\
(0.008)\end{array}$ & $\begin{array}{l}0.015^{*} \\
(0.008)\end{array}$ & $\begin{array}{l}0.013^{*} \\
(0.008)\end{array}$ & $\begin{array}{l}0.013^{*} \\
(0.007)\end{array}$ \\
\hline MDP $\times$ "winner plant" industry & $\begin{array}{l}0.011^{* *} \\
(0.005)\end{array}$ & & $\begin{array}{l}0.581^{* *} \\
(0.240)\end{array}$ & & $\begin{array}{l}0.324^{*} \\
(0.168)\end{array}$ & \\
\hline $\mathrm{MDP} \times \mathrm{MDP}$ industry & & $\begin{array}{l}0.012^{* *} \\
(0.005)\end{array}$ & & $\begin{array}{l}0.533^{* *} \\
(0.263)\end{array}$ & & $\begin{array}{l}0.356^{* *} \\
(0.175)\end{array}$ \\
\hline Plant FE & Yes & Yes & Yes & Yes & Yes & Yes \\
\hline Industry $\times$ county $\times$ year FE & Yes & Yes & Yes & Yes & Yes & Yes \\
\hline Case FE & Yes & Yes & Yes & Yes & Yes & Yes \\
\hline R-squared & 0.88 & 0.88 & 0.88 & 0.88 & 0.88 & 0.88 \\
\hline Observations & 423,000 & 423,000 & 423,000 & 423,000 & 423,000 & 423,000 \\
\hline
\end{tabular}




\section{Table 6: Local Employment and Wage Spillovers}

This table presents variants of the regressions in Table 2 in which the dependent variable is either plant-level employment or plant-level wages. Observations are weighted by plant-level employment. Standard errors are double clustered at the county and year level. The sample period is from 1977 to 1998. ${ }^{*},{ }^{* *}$, and ${ }^{* * *}$ denotes significance at the $10 \%, 5 \%$, and $1 \%$ level, respectively.

\begin{tabular}{|c|c|c|c|c|}
\hline & \multicolumn{2}{|c|}{ Employment } & \multicolumn{2}{|c|}{ Wages } \\
\hline & $(1)$ & (2) & (3) & $(4)$ \\
\hline MDP & $\begin{array}{c}0.035^{* * *} \\
(0.013)\end{array}$ & & $\begin{array}{l}0.037^{* *} \\
(0.016)\end{array}$ & \\
\hline MDP $\times(<50$ miles $)$ & & $\begin{array}{c}0.037^{* * *} \\
(0.013)\end{array}$ & & $\begin{array}{l}0.039^{* *} \\
(0.017)\end{array}$ \\
\hline $\mathrm{MDP} \times(50$ to 100 miles $)$ & & $\begin{array}{l}0.021^{* *} \\
(0.010)\end{array}$ & & $\begin{array}{c}0.015 \\
(0.014)\end{array}$ \\
\hline $\mathrm{MDP} \times(100$ to 250 miles $)$ & & $\begin{array}{c}0.005 \\
(0.006)\end{array}$ & & $\begin{array}{c}0.004 \\
(0.010)\end{array}$ \\
\hline Plant FE & Yes & Yes & Yes & Yes \\
\hline Industry $\times$ year FE & Yes & Yes & Yes & Yes \\
\hline Case FE & Yes & Yes & Yes & Yes \\
\hline R-squared & 0.97 & 0.96 & 0.80 & 0.75 \\
\hline Observations & 157,000 & $2,209,000$ & 157,000 & $2,209,000$ \\
\hline
\end{tabular}




\section{Table 7: Global Employment and Wage Spillovers}

This table presents variants of the regressions in Table 3 in which the dependent variable is either plant-level employment or plant-level wages. Observations are weighted by plant-level employment. Standard errors are double clustered at the county and year level. The sample period is from 1977 to $1998 .{ }^{*},{ }^{* *}$, and ${ }^{* *}$ denotes significance at the $10 \%, 5 \%$, and $1 \%$ level, respectively.

\begin{tabular}{|c|c|c|c|c|c|c|}
\hline & \multicolumn{3}{|c|}{ Employment } & \multicolumn{3}{|c|}{ Wages } \\
\hline & $(1)$ & $(2)$ & (3) & $(4)$ & (5) & (6) \\
\hline MDP & $\begin{array}{l}0.017^{* * *} \\
(0.006)\end{array}$ & $\begin{array}{l}0.017^{* *} \\
(0.007)\end{array}$ & $\begin{array}{l}0.016^{* *} \\
(0.007)\end{array}$ & $\begin{array}{c}0.001 \\
(0.004)\end{array}$ & $\begin{array}{c}0.003 \\
(0.005)\end{array}$ & $\begin{array}{c}0.002 \\
(0.004)\end{array}$ \\
\hline Plant FE & Yes & Yes & Yes & Yes & Yes & Yes \\
\hline Industry $\times$ county $\times$ year FE & No & Yes & Yes & No & Yes & Yes \\
\hline Industry $\times$ year FE & Yes & - & - & Yes & - & - \\
\hline Case FE & Yes & - & Yes & Yes & - & Yes \\
\hline Control group & $\begin{array}{l}\text { Plants of } \\
\text { runner-up firms }\end{array}$ & $\begin{array}{c}\text { Plants of } \\
\text { MC firms } \\
\text { in same county }\end{array}$ & $\begin{array}{l}\text { Plants of } \\
\text { runner-up firms } \\
\text { in same county }\end{array}$ & $\begin{array}{c}\text { Plants of } \\
\text { runner-up firms }\end{array}$ & $\begin{array}{c}\text { Plants of } \\
\text { MC firms } \\
\text { in same county }\end{array}$ & $\begin{array}{c}\text { Plants of } \\
\text { runner-up firms } \\
\text { in same county }\end{array}$ \\
\hline R-squared & 0.98 & 0.96 & 0.98 & 0.58 & 0.62 & 0.58 \\
\hline Observations & $1,407,000$ & $1,046,000$ & 423,000 & $1,407,000$ & $1,046,000$ & 423,000 \\
\hline
\end{tabular}




\section{Table 8: Estimation Results}

Panel A shows the parameter estimates along with the standard errors. Panel B shows the model moments along with the reduced-form estimates. Targeted refers to moments that are targeted in the estimation.

Panel A: Parameter Estimates

\begin{tabular}{lcc}
\hline & Estimate & Standard error \\
\cline { 2 - 3 }$\kappa$ & 0.039 & 0.008 \\
$\theta$ & 0.94 & 0.293 \\
$\rho$ & 0.61 & 0.333 \\
$\nu$ & 0.013 & 0.004 \\
\hline
\end{tabular}

Panel B: Model Moments vs. Data Moments

\begin{tabular}{lcc}
\hline & Data & Model \\
\cline { 2 - 3 } Targeted & & \\
TFP (local) & 0.04 & 0.04 \\
TFP (global) & 0.018 & 0.018 \\
Employment (global) & 0.016 & 0.016 \\
Wages (global) & 0.002 & 0.002 \\
Non-targeted & & \\
Employment (local) & 0.035 & 0.034 \\
Wages (local) & 0.037 & 0.027 \\
\hline
\end{tabular}




\section{Table 9: Worker-Level Heterogeneity}

This table shows changes in worker-level utility (in \%) from a $4 \%$ increase in productivity in one state for i) workers in the shocked state, ii) workers in other states at plants that are not connected to the shocked state, and iii) workers in other states at plants that are connected to the shocked state. All 50 states are independently shocked; the table reports averages across all 50 experiments.

\begin{tabular}{lcc}
\hline & $\begin{array}{c}\text { Without } \\
\text { knowledge } \\
\text { sharing }\end{array}$ & $\begin{array}{c}\text { With } \\
\text { knowledge } \\
\text { sharing }\end{array}$ \\
\cline { 2 - 3 } Shocked & 1.19 & 1.22 \\
Non-connected & 0.029 & 0.056 \\
Connected & 0.028 & 0.30 \\
\hline
\end{tabular}




\section{Propagation and Amplification of Local Productivity Spillovers}

Xavier Giroud Simone Lenzu Quinn Maingi Holger Mueller

Online Appendix 


\section{A Additional Figures and Tables}

\section{Figure A.1: Geography of Economic Activity}

In Panel A, counties are sorted into deciles based on the number of plants in the 1987 County Business Patterns (CBP). The map is based on CBP data due to Census Bureau disclosure requirements. In Panel B, counties are sorted into deciles based on the number of plants in the model. A darker color indicates more plants. Counties with no available data in the 1987 CBP are shown in white.

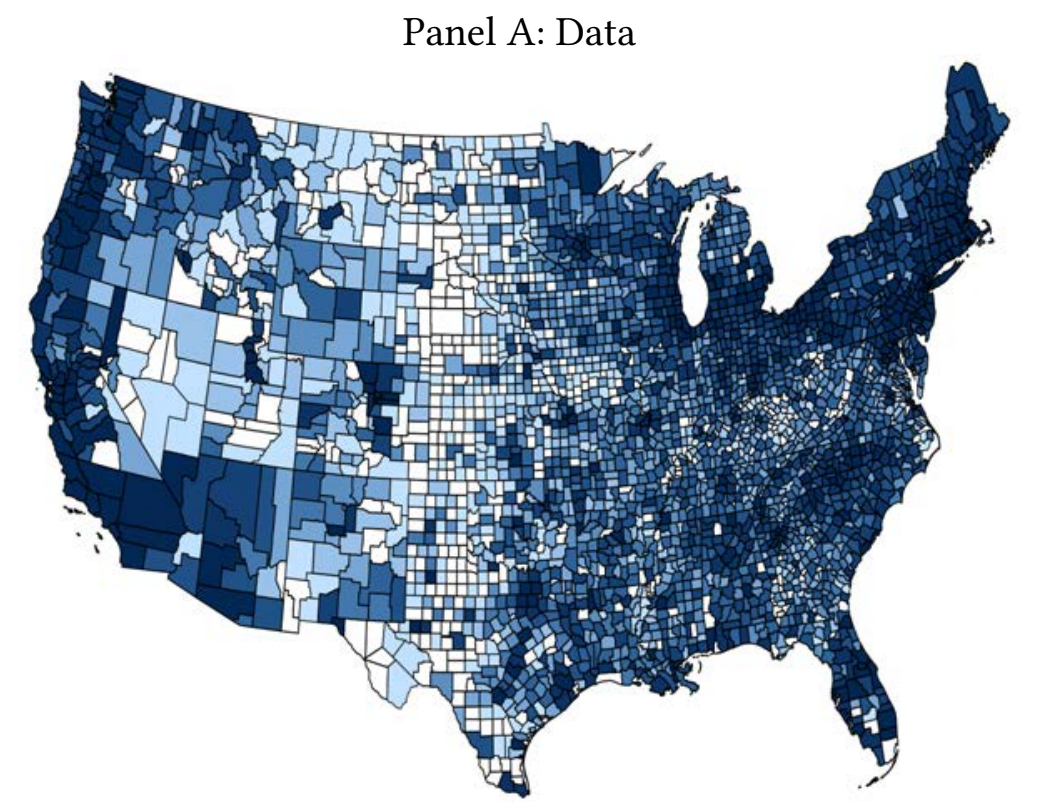

Panel B: Model

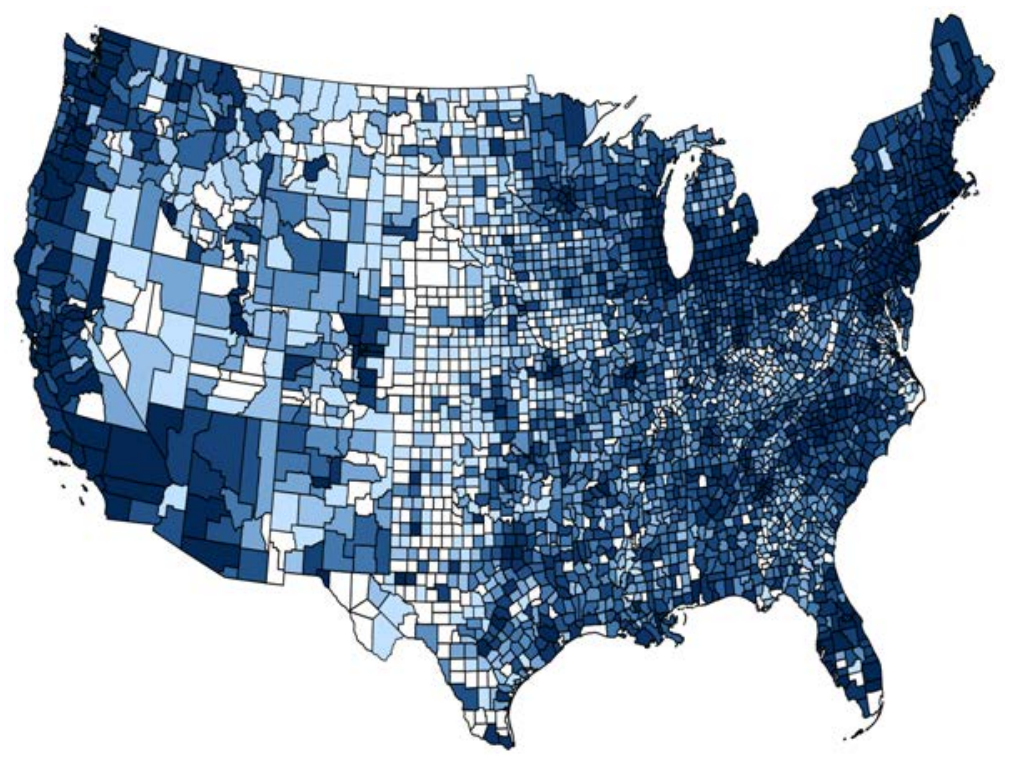

A.1 


\section{Table A.1: Treatment Effect Dynamics}

Columns (1) and (2) present variants of the regressions in column (1) of Table 2 (local productivity spillover) and column (3) of Table 3 (global productivity spillover), respectively, where Post is replaced with event-year dummies. MDP(0) denotes the year of the MDP opening. The base year is $\tau=-5$. Observations are weighted by plant-level employment. Standard errors are double clustered at the county and year level. The sample period is from 1977 to $1998 .{ }^{*},{ }^{* *}$, and ${ }^{* * *}$ denotes significance at the $10 \%, 5 \%$, and $1 \%$ level, respectively.

\begin{tabular}{|c|c|c|}
\hline & \multicolumn{2}{|c|}{ TFP } \\
\hline & (1) & $(2)$ \\
\hline \multirow[t]{2}{*}{$\operatorname{MDP}(-4)$} & -0.004 & 0.001 \\
\hline & $(0.024)$ & $(0.013)$ \\
\hline \multirow[t]{2}{*}{$\operatorname{MDP}(-3)$} & 0.006 & 0.004 \\
\hline & $(0.024)$ & $(0.011)$ \\
\hline \multirow[t]{2}{*}{ MDP(-2) } & -0.005 & -0.003 \\
\hline & $(0.021)$ & $(0.010)$ \\
\hline \multirow[t]{2}{*}{$\operatorname{MDP}(-1)$} & 0.002 & 0.001 \\
\hline & $(0.020)$ & $(0.009)$ \\
\hline \multirow[t]{2}{*}{$\operatorname{MDP}(0)$} & 0.017 & 0.006 \\
\hline & $(0.018)$ & $(0.008)$ \\
\hline \multirow[t]{2}{*}{$\operatorname{MDP}(1)$} & $0.038^{* *}$ & $0.015^{*}$ \\
\hline & $(0.018)$ & $(0.008)$ \\
\hline \multirow[t]{2}{*}{$\operatorname{MDP}(2)$} & $0.041^{* *}$ & $0.019^{*}$ \\
\hline & $(0.020)$ & $(0.010)$ \\
\hline \multirow[t]{2}{*}{$\operatorname{MDP}(3)$} & $0.049^{* * *}$ & $0.022^{* *}$ \\
\hline & $(0.022)$ & $(0.010)$ \\
\hline \multirow[t]{2}{*}{$\operatorname{MDP}(4)$} & $0.050^{* *}$ & $0.024^{* *}$ \\
\hline & $(0.023)$ & $(0.011)$ \\
\hline \multirow[t]{2}{*}{$\operatorname{MDP}(5)$} & $0.048^{* *}$ & $0.023^{* *}$ \\
\hline & $(0.022)$ & $(0.011)$ \\
\hline Plant FE & Yes & Yes \\
\hline Industry $\times$ year FE & Yes & - \\
\hline Industry $\times$ county $\times$ year FE & - & Yes \\
\hline Case FE & Yes & Yes \\
\hline R-squared & 0.88 & 0.88 \\
\hline Observations & 157,000 & 423,000 \\
\hline
\end{tabular}




\section{Table A.2: Input-Output Linkages (Local Productivity Spillover)}

This table presents variants of the regression in column (1) of Table 2 in which both terms in equation (1) are interacted with measures of either input flows or output flows between the industry of the incumbent plant and the industry of the MDP. The measures of input and output flows are

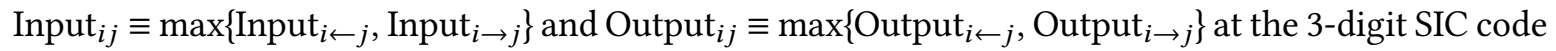
level from Ellison, Glaeser, and Kerr (2010), where Input $i \leftarrow j\left(\right.$ Output $\left._{i \rightarrow j}\right)$ is the share of industry $i$ 's inputs (outputs) that come from (are sold to) industry $j$. Observations are weighted by plant-level employment. Standard errors are double clustered at the county and year level. The sample period is from 1977 to $1998 .{ }^{*},{ }^{* *}$, and ${ }^{* * *}$ denotes significance at the $10 \%, 5 \%$, and $1 \%$ level, respectively.

\begin{tabular}{lcc}
\hline & \multicolumn{2}{c}{ TFP } \\
\cline { 2 - 3 } & Input flows & Output flows \\
& $(1)$ & $(2)$ \\
\cline { 2 - 3 } MDP & $0.037^{* *}$ & $0.038^{* *}$ \\
MDP $\times$ MDP industry & $(0.017)$ & $(0.016)$ \\
& 0.476 & 0.339 \\
Plant FE & $(0.520)$ & $(0.476)$ \\
Industry $\times$ year FE & Yes & Yes \\
Case FE & Yes & Yes \\
R-squared & Yes & Yes \\
Observations & 0.88 & 0.88 \\
& 157,000 & 157,000 \\
\hline
\end{tabular}




\section{Table A.3: Input-Output Linkages (Global Productivity Spillover)}

This table presents variants of the regression in column (3) of Table 3 in which both terms in equation (1) are interacted with measures of either input flows or output flows between the industry of the treated plant and either the industry of the firm's plant in the winner county ("winner plant") or the industry of the MDP. The measures of input and output flows are described in Table A.2. Observations are weighted by plant-level employment. Standard errors are double clustered at the county and year level. The sample period is from 1977 to $1998 .{ }^{*},{ }^{* *}$, and ${ }^{* * *}$ denotes significance at the $10 \%, 5 \%$, and $1 \%$ level, respectively.

\begin{tabular}{|c|c|c|c|c|}
\hline & \multicolumn{4}{|c|}{ TFP } \\
\hline & \multicolumn{2}{|c|}{ Input flows } & \multicolumn{2}{|c|}{ Output flows } \\
\hline & (1) & $(2)$ & (3) & $(4)$ \\
\hline MDP & $\begin{array}{l}0.016^{* *} \\
(0.008)\end{array}$ & $\begin{array}{l}0.017^{* *} \\
(0.008)\end{array}$ & $\begin{array}{l}0.017^{* *} \\
(0.008)\end{array}$ & $\begin{array}{l}0.017^{* *} \\
(0.008)\end{array}$ \\
\hline MDP $\times$ "winner plant" industry & $\begin{array}{c}0.242 \\
(0.291)\end{array}$ & & $\begin{array}{c}0.161 \\
(0.234)\end{array}$ & \\
\hline MDP $\times$ MDP industry & & $\begin{array}{c}0.194 \\
(0.276)\end{array}$ & & $\begin{array}{c}0.138 \\
(0.250)\end{array}$ \\
\hline Plant FE & Yes & Yes & Yes & Yes \\
\hline Industry $\times$ county $\times$ year $\mathrm{FE}$ & Yes & Yes & Yes & Yes \\
\hline Case FE & Yes & Yes & Yes & Yes \\
\hline R-squared & 0.88 & 0.88 & 0.88 & 0.88 \\
\hline Observations & 423,000 & 423,000 & 423,000 & 423,000 \\
\hline
\end{tabular}




\section{Table A.4: Financial Constraints (Local Productivity Spillover)}

This table presents variants of the regression in column (1) of Table 2 in which both terms in equation (1) are interacted with either the KZ-index of Kaplan and Zingales (1997) or the SA-index of Hadlock and Pierce (2010). Observations are weighted by plant-level employment. Standard errors are double clustered at the county and year level. The sample is restricted to firms that have a match in Compustat. The sample period is from 1977 to $1998 .{ }^{*},{ }^{* *}$, and ${ }^{* * *}$ denotes significance at the $10 \%$, $5 \%$, and $1 \%$ level, respectively.

\begin{tabular}{lcc}
\hline & \multicolumn{2}{c}{ TFP } \\
\cline { 2 - 3 } & KZ-index & SA-index \\
& $(1)$ & $(2)$ \\
\cline { 2 - 3 } MDP & $0.041^{* * *}$ & $0.040^{* * *}$ \\
MDP $\times$ FC & $(0.018)$ & $(0.017)$ \\
& -0.001 & -0.001 \\
Plant FE & $(0.002)$ & $(0.004)$ \\
Industry $\times$ year FE & Yes & Yes \\
Case FE & Yes & Yes \\
R-squared & Yes & Yes \\
Observations & 0.89 & 0.89 \\
& 42,000 & 42,000 \\
\hline
\end{tabular}




\section{Table A.5: Financial Constraints (Global Productivity Spillover)}

This table presents variants of the regression in column (3) of Table 3 in which both terms in equation (1) are interacted with either the KZ-index of Kaplan and Zingales (1997) or the SA-index of Hadlock and Pierce (2010). Observations are weighted by plant-level employment. Standard errors are double clustered at the county and year level. The sample is restricted to firms that have a match in Compustat. The sample period is from 1977 to $1998 .{ }^{*},{ }^{* *}$, and ${ }^{* * *}$ denotes significance at the $10 \%$, $5 \%$, and $1 \%$ level, respectively.

\begin{tabular}{lcc}
\hline & \multicolumn{2}{c}{ TFP } \\
\cline { 2 - 3 } & KZ-index & SA-index \\
& $(1)$ & $(2)$ \\
\cline { 2 - 3 } MDP & $0.018^{* *}$ & $0.019^{* *}$ \\
MDP $\times$ FC & $(0.008)$ & $(0.009)$ \\
& -0.000 & -0.001 \\
Plant FE & $(0.002)$ & $(0.002)$ \\
Industry $\times$ county $\times$ year FE & Yes & Yes \\
Case FE & Yes & Yes \\
R-squared & Yes & Yes \\
Observations & 0.90 & 0.90 \\
& 130,000 & 130,000 \\
\hline
\end{tabular}




\section{Table A.6: Industries, R\&D Flows, and Patent Citations (Local Productivity Spillover)}

This table presents variants of the regression in column (1) of Table 2. In column (1), both terms in equation (1) are interacted with a dummy variable indicating whether the incumbent plant is in the same 4-digit SIC code industry as the MDP. In columns (2) and (3), both terms in equation (1) are interacted with measures of either mutual $R \& D$ flows or mutual patent citations between the industry of the incumbent plant and the industry of the MDP. The measures of mutual R\&D flows and mutual patent citations are described in Section 2.5. Observations are weighted by plant-level employment. Standard errors are double clustered at the county and year level. The sample period is from 1977 to $1998 .{ }^{*},{ }^{* *}$, and ${ }^{* * *}$ denotes significance at the $10 \%, 5 \%$, and $1 \%$ level, respectively.

\begin{tabular}{lccc}
\hline & \multicolumn{3}{c}{ TFP } \\
\cline { 2 - 4 } & $\begin{array}{c}\text { Same } \\
\text { industry }\end{array}$ & $\begin{array}{c}\text { Mutual R\&D } \\
\text { flows }\end{array}$ & $\begin{array}{c}\text { Mutual patent } \\
\text { citations }\end{array}$ \\
& $(1)$ & $(2)$ & $(3)$ \\
\cline { 2 - 4 } MDP & $0.039^{* *}$ & $0.034^{* *}$ & $0.028^{*}$ \\
MDP $\times$ MDP industry & $(0.017)$ & $(0.017)$ & $(0.016)$ \\
& $0.032^{* *}$ & $0.997^{* *}$ & $0.723^{* *}$ \\
Plant FE & $(0.015)$ & $(0.401)$ & $(0.334)$ \\
Industry $\times$ year FE & Yes & Yes & Yes \\
Case FE & Yes & Yes & Yes \\
R-squared & Yes & Yes & Yes \\
Observations & 0.88 & 0.88 & 0.88 \\
& 157,000 & 157,000 & 157,000 \\
\hline
\end{tabular}




\section{Table A.7: Distance to MDP (Global Employment Spillover)}

This table presents variants of the regressions in Table 4 in which the dependent variable is plant-level employment. Observations are weighted by plant-level employment. Standard errors are double clustered at the county and year level. The sample period is from 1977 to 1998. * ${ }^{* *}$, and ${ }^{* * *}$ denotes significance at the $10 \%, 5 \%$, and $1 \%$ level, respectively.

\begin{tabular}{|c|c|c|c|c|c|}
\hline & \multicolumn{5}{|c|}{ Employment } \\
\hline & $\begin{array}{c}\text { Excluding plants } \\
\text { within } 100 \\
\text { miles of MDP }\end{array}$ & $\begin{array}{c}\text { Excluding plants } \\
\text { within } 250 \\
\text { miles of MDP }\end{array}$ & $\begin{array}{c}\text { Excluding plants } \\
\text { within } 500 \\
\text { miles of MDP }\end{array}$ & $\begin{array}{l}\text { Excluding plants } \\
\text { in MDP state }\end{array}$ & $\begin{array}{c}\text { Excluding plants } \\
\text { in MDP Census } \\
\text { division }\end{array}$ \\
\hline & $(1)$ & (2) & (3) & (4) & (5) \\
\hline MDP & $\begin{array}{l}0.017^{* *} \\
(0.007)\end{array}$ & $\begin{array}{l}0.016^{* *} \\
(0.008)\end{array}$ & $\begin{array}{l}0.016^{* *} \\
(0.008)\end{array}$ & $\begin{array}{l}0.016^{* *} \\
(0.008)\end{array}$ & $\begin{array}{l}0.017^{* *} \\
(0.008)\end{array}$ \\
\hline Plant FE & Yes & Yes & Yes & Yes & Yes \\
\hline Industry $\times$ county $\times$ year FE & Yes & Yes & Yes & Yes & Yes \\
\hline Case FE & Yes & Yes & Yes & Yes & Yes \\
\hline R-squared & 0.98 & 0.98 & 0.98 & 0.98 & 0.98 \\
\hline Observations & 402,000 & 365,000 & 286,000 & 395,000 & 345,000 \\
\hline
\end{tabular}




\section{B Model Appendix}

\section{B.1 Derivations}

\section{B.1.1 Consumer Problem}

In this section, we derive the labor supply functions and equilibrium utility implied by the solution to the consumer's problem. Equation (3) implies that the CDF of indirect utility is given by:

$$
\mathbb{P}\left(\bigcap_{n=1}^{N} \bigcap_{j \in \mathscr{E}_{n}}\left\{b_{n j} \frac{w_{n j}}{P_{n}^{\alpha} R_{n}^{1-\alpha}} \leq t_{n j},\right\}\right)=\exp \left\{-\sum_{n \in N}\left(\sum_{j \in \mathscr{E}_{n}} B_{n}^{\frac{1}{1-\rho}}\left(\frac{w_{n j}}{P_{n}^{\alpha} R_{n}^{1-\alpha}}\right)^{\frac{\epsilon}{1-\rho}} t_{n j}^{-\frac{\epsilon}{1-\rho}}\right)^{1-\rho}\right\}
$$

Using the notation of Lind and Ramondo (2021), the multivariate Fréchet CDF in equation (A.1) is generated by the Archimedean copula:

$$
G\left(\left\{x_{n j}\right\}_{n \in N: j \in \mathscr{E}_{n}}\right)=\sum_{n \in n}\left(\sum_{j \in \mathscr{E}_{n}} x_{n j}^{\frac{1}{1-\rho}}\right)^{1-\rho},
$$

with scale parameters $T_{n j}=B_{n}\left(\frac{w_{n j}}{P_{n}^{\alpha} R_{n}^{1-\alpha}}\right)^{\epsilon}$. By Lemma A.4 in Lind and Ramondo (2021), average equilibrium utility is given by:

$$
\bar{U}=\Gamma\left(\frac{\epsilon-1}{\epsilon}\right)\left[\sum_{n \in N} B_{n}\left(\frac{W_{n}^{b}}{P_{n}^{\alpha} R_{n}^{1-\alpha}}\right)^{\epsilon}\right]^{\frac{1}{\epsilon}} .
$$

Moreover, by Lemma A.5 (part 1) in Lind and Ramondo (2021), (supply-side) plant labor shares are given by:

$$
\frac{l_{n j}^{S}}{\bar{L}}=\mathbb{P}\{\eta \text { chooses plant } j \text { in location } n\}=\frac{\left(\sum_{k \in \mathscr{E}_{n}} B_{n}^{\frac{1}{1-\rho}}\left(\frac{w_{n k}}{P_{n}^{\alpha} R_{n}^{1-\alpha}}\right)^{\frac{\epsilon}{1-\rho}}\right)^{-\rho} B_{n}^{\frac{1}{1-\rho}}\left(\frac{w_{n j}}{P_{n}^{\alpha} R_{n}^{1-\alpha}}\right)^{\frac{\epsilon}{1-\rho}}}{\sum_{n \in N} B_{n}\left(\sum_{k \in \mathscr{C}_{n}}\left(\frac{w_{n k}}{P_{n}^{\alpha} R_{n}^{1-\alpha}}\right)^{\frac{\epsilon}{1-\rho}}\right)^{1-\rho}} .
$$

This implies across-location labor shares are given by:

$$
\frac{L_{n}}{\bar{L}} \equiv \mathbb{P}\{\eta \text { chooses } n\}=\frac{B_{n}\left(\frac{W_{n}^{b}}{P_{n}^{\alpha} R_{n}^{1-\alpha}}\right)^{\epsilon}}{\sum_{\ell \in N} B_{\ell}\left(\frac{W_{\ell}^{b}}{P_{\ell}^{\alpha} R_{\ell}^{1-\alpha}}\right)^{\epsilon}},
$$

and within-location (supply-side) labor shares are given by: 


$$
\frac{l_{n j}^{S}}{L_{n}}=\mathbb{P}\{\eta \text { chooses } j \mid \eta \text { chooses } \mathrm{n}\}=\frac{w_{n j}^{\frac{\epsilon}{1-\rho}}}{\sum_{k: n \in \mathcal{E}_{k}} w_{n k}^{\frac{\epsilon}{1-\rho}}} .
$$

\section{B.1.2 Plant Problem}

In this section, we provide the solution to the plant's problem. For formulae provided in this section, assume plants are ordered in descending order by $\frac{\bar{z}_{i j}}{w_{i j}}$ (e.g., $j=1$ corresponds to the most efficient plant) for all references to plant identity. Let $J_{i}:=\left|\mathscr{E}_{i}\right|$ denote the number of plants in location $i$.

Distribution of Productivity and Efficiency Wages. Let $Z_{i j}$ be the random variable corresponding to firm $j$ 's idiosyncratic productivity draw $z_{i j}(\omega)$. Since $\frac{1}{Z_{i j}}$ is Pareto distributed with scale parameter $\frac{1}{\bar{z}_{i j}}$ and shape parameter $v$, the CDF of $\frac{1}{Z_{i j}}$ is given by:

$$
F_{\frac{1}{z_{i j}}}(z)=\mathbf{1}_{z>\frac{1}{\bar{z}_{i j}}}\left(1-\left(\bar{z}_{i j} z\right)^{-v}\right) \text {. }
$$

The random variable $\bar{W}_{i j}:=\frac{w_{i j}}{Z_{i j}}$ corresponds to firm $j$ 's idiosyncratic efficiency wages. Its $\mathrm{CDF}$ is given by:

$$
F_{\bar{W}_{i j}}(t)=1_{t>\frac{w_{i j}}{\bar{z}_{i j}}}\left(1-\left(\frac{\bar{z}_{i j}}{w_{i j}} t\right)^{-v}\right),
$$

with corresponding density:

$$
f_{\bar{W}_{i j}}(t)=\mathbf{1}_{t>\frac{w_{i j}}{\bar{z}_{i j}}} v t^{-v-1}\left(\frac{\bar{z}_{i j}}{w_{i j}}\right)^{-v} .
$$

The random variable $\bar{W}_{i}:=\min _{j} \bar{W}_{i j}$ represents (equilibrium) region-level idiosyncratic efficiency wages. Its $\mathrm{CDF}$ is given by:

$$
F_{\bar{W}_{i}}(t)=1-\Pi_{j \in \mathscr{C}_{i}}\left(1-F_{\bar{W}_{i j}}(t)\right),
$$

with corresponding density:

$$
f_{\bar{W}_{i}}(t)=v\left|\left\{j \in \mathscr{E}_{i}: t \geq \frac{w_{i j}}{\bar{z}_{i j}}\right\}\right| t^{-1} \Pi_{j \in \mathscr{E}_{i}: t \geq \frac{w_{i j}}{\bar{z}_{i j}}}\left[\left(\frac{\bar{z}_{i j}}{w_{i j}} t\right)^{-v}\right] .
$$

Output Shares. We derive within-market plant-level output shares as an intermediate quantity that is useful for both productivity and labor shares. Output shares are given by: 


$$
\begin{aligned}
s_{i j} & =\mathbb{P}\{j \text { produces } \omega\}=\mathbb{P}\left\{\bar{W}_{i j}=\bar{W}_{i}\right\} \\
& \equiv \mathbb{P}\left(\bigcap_{k \neq j}\left\{\bar{W}_{i j}<\bar{W}_{i k}\right\}\right)=\int_{0}^{\infty} f_{\bar{W}_{i j}}(t) \Pi_{k \neq j}\left(1-F_{\bar{W}_{i k}}(t)\right) d t .
\end{aligned}
$$

Plugging in equations (A.2) and (A.3) and solving the integral gives:

$$
s_{i j}=\frac{1}{j}\left(\frac{\left(\frac{\bar{z}_{i j}}{w_{i j}}\right)^{j}}{\Pi_{k=1}^{j}\left(\frac{\bar{z}_{i k}}{w_{i k}}\right)}\right)^{v}-\sum_{\mathcal{M}=j+1}^{J_{i}} \frac{1}{\mathcal{M}(\mathcal{M}-1)}\left(\frac{\left(\frac{\bar{z}_{i \mathcal{M}}}{w_{i \mathcal{M}}}\right)^{\mathcal{M}}}{\Pi_{k=1}^{\mathcal{M}}\left(\frac{\bar{z}_{i k}}{w_{i k}}\right)}\right)^{v} .
$$

Realized Productivity and Inverse Productivity. For realized productivity, we have the following expression:

$$
\begin{aligned}
\hat{z}_{i j} & =\mathbb{E}_{\omega}\left[z_{i j}(\omega) \mid j \text { produces } \omega\right] \\
& \equiv \mathbb{E}\left[\frac{w_{i j}}{\bar{W}_{i j}} \mid \bar{W}_{i j}=\bar{W}_{i}\right]=\frac{w_{i j}}{s_{i j}} \int_{0}^{\infty} \frac{1}{t} f_{\bar{W}_{i j}}(t) \Pi_{k \neq j}\left(1-F_{\bar{W}_{i k}}(t)\right) d t .
\end{aligned}
$$

Plugging in equations (A.2), (A.3), and (A.6), and solving the integral gives:

$$
\begin{aligned}
\hat{z}_{i j} & =\frac{w_{i j}}{s_{i j}}\left(\frac{v}{v j+1} \frac{\left(\frac{\bar{z}_{i j}}{w_{i j}}\right)^{j v+1}}{\Pi_{k=1}^{j}\left(\frac{\bar{z}_{i k}}{w_{i k}}\right)^{v}}-\sum_{\mathcal{M}=j+1}^{J_{i}} \frac{v^{2}}{(\mathcal{M} v+1)((\mathcal{M}-1) v+1)} \frac{\left(\frac{\bar{z}_{i \mathcal{M}}}{w_{i \mathcal{M}}}\right)^{\mathcal{M} v+1}}{\Pi_{k=1}^{\mathcal{M}}\left(\frac{\bar{z}_{i k}}{w_{i k}}\right)^{v}}\right) \\
= & \underbrace{\frac{v}{v+1} \bar{z}_{i j}}_{=\mathbb{E}\left[Z_{i j}\right]} \underbrace{\left(\frac{\left.\frac{v+1}{v j+1}-\sum_{\mathcal{M}=j+1}^{J_{i}} \frac{\left(\frac{\bar{z}_{i \mathcal{M}}}{w_{i \mathcal{M}}}\right)^{\mathcal{M} v+1}}{(\mathcal{M} v+1)((\mathcal{M}-1) v+1)} \frac{\left(\frac{z_{i j}}{w_{i j}}\right)^{j v+1} \Pi_{k=j+1}^{\mathcal{M}}\left(\bar{z}_{i k}\right.}{w_{i k}}\right)^{v}}{\sum_{\mathcal{M}=j+1}^{J_{i}} \frac{1}{\mathcal{M}(\mathcal{M}-1)} \frac{\left(\frac{\bar{z}_{i j} \mathcal{M}}{w_{i \mathcal{M}}}\right)^{\mathcal{M} v}}{\left(\bar{z}_{i j}\right)^{j v} \Pi_{k=j+1}^{\mathcal{M}}\left(\frac{\bar{z}_{i k}}{w_{i k}}\right)^{v}}}\right)}_{=\mathcal{R S}\left(v,\left\{\frac{\bar{z}_{i k}}{w_{i k}}\right\}_{k \in \mathscr{E}_{i}}\right)} .
\end{aligned}
$$

This gives the exact form of $\mathcal{R} \mathcal{S}_{i j}$ in equation (17). Let $\underline{z}_{i j}$ represent realized inverse productivity:

$$
\underline{\mathrm{z}}_{i j} \equiv \mathbb{E}_{\omega}\left[\frac{1}{z_{i j}(\omega)} \mid j \text { produces } \omega\right]=\frac{1}{s_{i j} w_{i j}} \int_{0}^{\infty} t f_{\bar{W}_{i j}}(t) \Pi_{k \neq j}\left(1-F_{\bar{W}_{i k}}(t)\right) d t .
$$


Plugging in equations (A.2) and (A.3) and solving the integral gives:

$$
\underline{\mathrm{z}}_{i j}=\frac{1}{s_{i j} w_{i j}}\left(\frac{v}{v j-1} \frac{\left(\frac{\bar{z}_{i j}}{w_{i j}}\right)^{j v-1}}{\Pi_{k=1}^{j}\left(\frac{\bar{z}_{i k}}{w_{i k}}\right)^{v}}-\sum_{\mathcal{M}=j+1}^{J_{i}} \frac{v^{2}}{(\mathcal{M} v-1)((\mathcal{M}-1) v-1)} \frac{\left(\frac{\bar{z}_{i \mathcal{M}}}{w_{i \mathcal{M}}}\right)^{\mathcal{M} v-1}}{\Pi_{k=1}^{\mathcal{M}}\left(\frac{\bar{z}_{i k}}{w_{i k}}\right)^{v}}\right) .
$$

Labor Demand. Our production technology implies that plant-level labor $\left(l_{i j}\right)$ per unit of final goods produced in location $i\left(q_{i}\right)$ is $\frac{l_{i j}}{q_{i}}=s_{i j} \underline{z}_{i j}$. Summing over all plants $j \in \mathscr{E}_{i}$ gives:

$$
\frac{L_{i}}{q_{i}}=\sum_{j \in \mathscr{E}_{i}} s_{i j} \underline{\mathrm{Z}}_{i j}
$$

This implies that within-location (demand-side) labor shares are given by:

$$
\frac{l_{i j}^{D}}{L_{i}}=\mathcal{L} \mathcal{D}_{i j}=\frac{s_{i j} \underline{\mathrm{Z}}_{i j}}{\sum_{k \in \mathscr{C}_{i}} s_{i k} \underline{\mathrm{Z}}_{i k}} .
$$

With some manipulation, plugging in equation (A.8) gives:

$$
\mathcal{L} \mathcal{D}_{i j}:=\frac{\frac{1}{w_{i j}}\left(\frac{\left(\frac{\bar{z}_{i j}}{w_{i j}}\right)^{j v-1}}{\Pi_{k=1}^{j}\left(\frac{\bar{z}_{i k}}{w_{i k}}\right)^{v}}-\sum_{\mathcal{M}=j+1}^{J_{i}} \frac{v(v j-1)}{(\mathcal{M} v-1)((\mathcal{M}-1) v-1)}\left(\frac{\bar{z}_{i \mathcal{M}}}{w_{i \mathcal{M}}}\right)^{\mathcal{M} v-1} \Pi_{k=1}^{\mathcal{M}}\left(\frac{\bar{z}_{i k}}{w_{i k}}\right)^{-v}\right)}{\sum_{\mathcal{K} \in \mathscr{E}_{i}} \frac{1}{w_{i \mathcal{K}}}\left(\frac{\left(\frac{\bar{z}_{i \mathcal{K}}}{w_{i \mathcal{K}}}\right)^{\mathcal{K} v-1}}{\Pi_{k=1}^{\mathcal{K}}\left(\frac{\bar{z}_{i k}}{w_{i k}}\right)^{v}}-\sum_{\mathcal{M}=\mathcal{K}+1}^{J_{i}} \frac{v(v \mathcal{K}-1)}{(\mathcal{M} v-1)((\mathcal{M}-1) v-1)}\left(\frac{\bar{z}_{i \mathcal{M}}}{w_{i \mathcal{M}}}\right)^{\mathcal{M} v-1} \Pi_{k=1}^{\mathcal{M}}\left(\frac{\bar{z}_{i k}}{w_{i k}}\right)^{-v}\right)} .
$$

This provides the exact form of $\mathcal{L} \mathcal{D}_{i j}$ in equation (16).

County-Level Efficiency Wages. Equilibrium county-level efficiency wages are given by the following expression:

$$
W_{i}^{z} \equiv \mathbb{E}\left[\bar{W}_{i}\right]=\int_{0}^{\infty} t f_{\bar{W}_{i}}(t) d t=\sum_{j=1}^{J_{i}}\left(\frac{\bar{z}_{i j}}{w_{i j}}\right)^{-1}\left(\frac{\left(\frac{\bar{z}_{i j}}{w_{i j}}\right)^{j}}{\Pi_{k \leq j} \frac{\bar{z}_{i k}}{w_{i k}}}\right)^{v}\left(-\frac{v}{(v j-1)(v(j-1)-1)}\right)=: \mathcal{Z} .
$$

This gives the exact form of $\mathcal{Z}$ in equation (19). 


\section{B.2 Proofs}

\section{B.2.1 Uniqueness of the Equilibrium}

In this section, we provide the proof of Proposition 1. We prove two intermediate claims before proving the proposition.

Claim 1. For each market $n$, given dispersion in productivity scale parameters, captured by $\left\{K_{-n}^{j}\right\}_{j \in \mathscr{C}_{n}}$, there exists unique within-county labor shares and relative wages $\left\{\frac{l_{n j}}{L_{n}}, \frac{w_{n j}}{W_{n}}\right\}_{j \in \mathscr{C}_{n}}$ that satisfy equations (14) and (16).

Proof. The within-location labor market equilibrium is characterized by setting within-location labor supply (equation (14)) equal to within-location labor demand (equation (16)):

$$
D_{n j}\left(\left\{w_{n k}\right\}_{k: n \in \mathcal{E}_{k}}\right):=\frac{l_{n j}^{D}}{L_{n}}\left(\left\{w_{n k}\right\}_{k \in \mathscr{C}_{n}}\right)-\frac{l_{n j}^{S}}{L_{n}}\left(\left\{w_{n k}\right\}_{k \in \mathscr{C}_{n}}\right)=0 .
$$

If equation (A.13) characterizes an excess demand system with the gross substitution property, equilibrium labor shares and relative wages are unique. This requires four properties: (i) $D_{n j}$ is continuous, (ii) $D_{n j}$ is homogeneous of degree zero, (iii) $\sum_{j \in \mathscr{E}_{n}} D_{n j}=0$, and (iv) $D_{n j}$ exhibits gross substitution in wages.

It is straightforward to show that labor demand is continuous by plugging equation (A.8) into equation (A.10) and applying the dominated convergence theorem; by inspection of equation (14), labor supply is clearly continuous. Thus, property (i) holds. Properties (ii) and (iii) follows immediately by inspection of equations (14) and (A.11). ${ }^{33}$ We show that property (iv) holds for each of supply and demand. For labor supply, using the labor supply function in equation (14) we have:

$$
\begin{aligned}
& \frac{\partial}{\partial w_{n \mathcal{M}}} \frac{w_{n j}^{\frac{\epsilon}{1-\rho}}}{\sum_{k \in \mathscr{C}_{n}} w_{n k}^{\frac{\epsilon}{1-\rho}}}=\frac{\epsilon}{1-\rho} \frac{-w_{n j}^{\frac{\epsilon}{1-\rho}} w_{n \mathcal{M}}^{\frac{\epsilon}{1-\rho}-1}}{\left(\sum_{k \in \mathscr{E}_{n}} w_{n k}^{\frac{\epsilon}{1-\rho}}\right)^{2}}<0, \\
& \frac{\partial}{\partial w_{n j}} \frac{w_{n j}^{\frac{\epsilon}{1-\rho}}}{\sum_{k \in \mathscr{E}_{n}} w_{n k}^{\frac{\epsilon}{1-\rho}}}=\frac{\epsilon}{1-\rho} w_{n j}^{\frac{\epsilon}{1-\rho}-1} \frac{\sum_{k \in \mathscr{C}_{n} \backslash\{j\}} w_{n k}^{\frac{\epsilon}{1-\rho}}}{\left(\sum_{k \in \mathscr{C}_{n}} w_{n k}^{\frac{\epsilon}{1-\rho}}\right)^{2}}>0 .
\end{aligned}
$$

\footnotetext{
${ }^{33}$ Note that labor demand is also homogeneous of degree zero in $\left\{\bar{z}_{n k}\right\}_{k \in \mathscr{E}_{n}}$; this property ensures that the within-location equilibrium depends only on $\left\{K_{-n}^{j}\right\}_{j \in \mathscr{E}_{n}}$.
} 
For labor demand, define $\mathscr{L} \mathscr{D}_{i j}:=\int_{0}^{\infty} t \frac{1}{w_{i j}} f_{\bar{W}_{i j}}(t) \Pi_{k \neq j}\left(1-F_{\bar{W}_{i k}}(t)\right) d t$. From equations

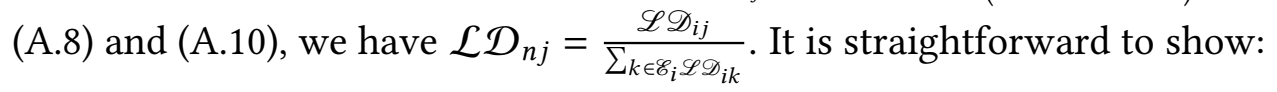

$$
\begin{gathered}
\frac{\partial \mathscr{L} \mathscr{D}_{i j}}{\partial w_{i k}}=\frac{v}{w_{i k}} \mathscr{L} \mathscr{D}_{i j}, \\
\frac{\partial \mathscr{L} \mathscr{D}_{i j}}{\partial w_{i j}}=\frac{1}{w_{i j}}\left((v-1) \mathscr{L} \mathscr{D}_{i j}-v \Pi_{k \neq j}\left(1-F_{\bar{W}_{i k}}\left(\frac{w_{i j}}{\bar{z}_{i j}}\right)\right)\right)<\frac{v}{w_{i j}} \mathscr{L} \mathscr{D}_{i j},
\end{gathered}
$$

which implies $\frac{\partial \mathcal{L} \mathcal{D}_{n j}}{\partial w_{i j}}<0$ and $\frac{\partial \mathcal{L} \mathcal{D}_{n j}}{\partial w_{i k}}>0 \forall k \in \mathscr{E}_{i} \backslash\{j\}$.

Claim 2. For each market $n$, there exist unique functions $g_{n}, h_{n}: \mathbb{R}_{++}^{J_{n}} \rightarrow \mathbb{R}_{++}$such that, $\forall\left\{w_{n j}\right\}_{j \in \mathscr{C}_{n}}$ that satisfy equation (A.13), the following holds: (1) $W_{n}^{b}=W_{n} g_{n}\left(\left\{K_{-n}^{j}\right\}_{j \in \mathscr{C}_{n}}\right)$, and (2) $W_{n}^{z}=W_{n} L_{n}^{-\beta} K_{n}^{-1} h_{n}\left(\left\{K_{-n}^{j}\right\}_{j \in \mathscr{E}_{n}}\right)$.

Proof. We can re-write equation (13) as $W_{n}^{b}=W_{n}\left(\sum_{j \in \mathscr{C}_{n}}\left(\frac{w_{n j}}{W_{n}}\right)^{\frac{\epsilon}{1-\rho}}\right)^{\frac{1-\rho}{\epsilon}}$. By Claim 1, $\forall n, j$, we can express the unique relative wage $\frac{w_{n j}}{W_{n}}=\tilde{g}_{n j}\left(\left\{K_{-n}^{j}\right\}_{j \in \mathscr{E}_{n}}\right)$ for some unique function $\tilde{g}_{n j}: \mathbb{R}_{++}^{J_{n}} \rightarrow \mathbb{R}_{++}$Thus:

$$
W_{n}^{b}=W_{n} \underbrace{\left.\sum_{j \in \mathscr{E}_{n}}\left(\tilde{g}_{n j}\left(\left\{K_{-n}^{j}\right\}_{j \in \mathscr{E}_{n}}\right)\right)^{\frac{\epsilon}{1-\rho}}\right)^{\frac{1-\rho}{\epsilon}}}_{=: g_{n}\left(\left\{K_{-n}^{j}\right\}_{j \in \mathscr{E}_{n}}\right)} .
$$

Similarly, we can re-write efficiency wages (equation (A.12)) as:

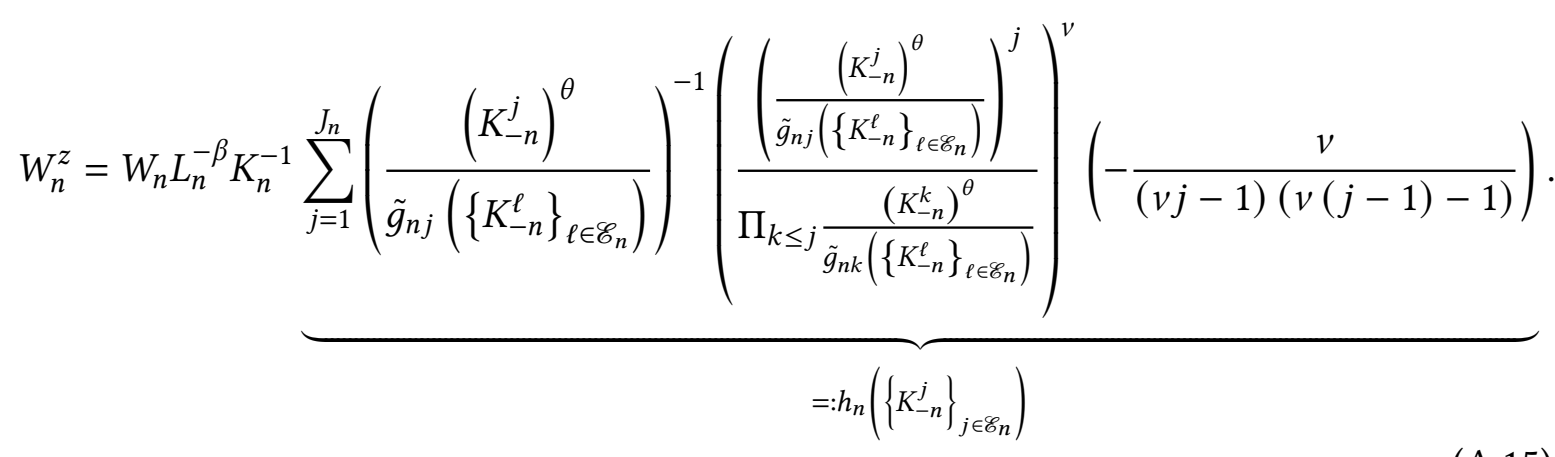


Using the results in Claims 1 and 2, we proceed with the proof of Proposition 1.

Proposition 1. Given parameter values $\{\alpha, \beta, \sigma, \epsilon, \theta, v, \rho\}$ and fundamentals $\{\boldsymbol{H}, \boldsymbol{B}, \boldsymbol{K}, \boldsymbol{E}, \boldsymbol{\tau}\}$, if $\frac{\alpha \epsilon-\epsilon-1}{\alpha \epsilon}+\beta<0$ and $\frac{1+\sigma \beta+(\sigma-1) \frac{\alpha \epsilon-\epsilon-1}{\alpha \epsilon}}{1+\beta(1-\sigma)-\sigma \frac{\alpha \epsilon-\epsilon-1}{\alpha \epsilon}} \in[-1,1]$, the equilibrium of the model exists and is unique (up to a normalization in wages).

Proof. Equations (10), (12), (15), and (A.14) imply:

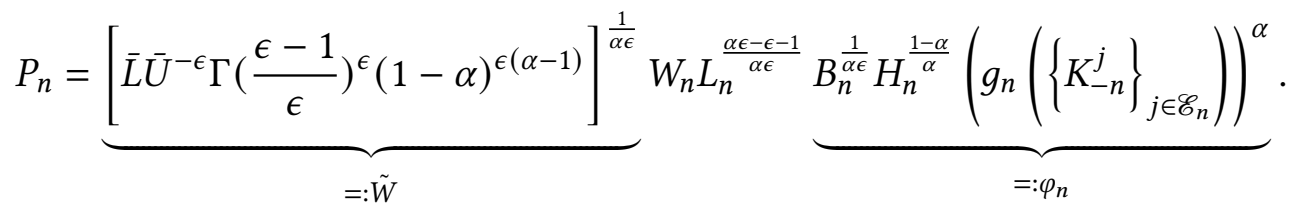

Let $\vartheta_{n}:=K_{n}^{-1} h_{n}\left(\left\{K_{-i}^{j}\right\}_{j \in \mathscr{C}_{i}}\right)$. Setting equation (A.16) equal to equation (8) and plugging in equations (18) and (A.15) gives:

$$
W_{n}^{1-\sigma} L_{n}^{(1-\sigma) \frac{\alpha \epsilon-\epsilon-1}{\alpha \epsilon}}=\sum_{i \in N} \tilde{W}^{\sigma-1} W_{i}^{1-\sigma} L_{i}^{\beta(\sigma-1)} \vartheta_{i}^{1-\sigma} \varphi_{n}^{\sigma-1} \tau_{n i}^{1-\sigma} .
$$

Plugging equations (18), (A.15), and (A.16) into equation (11) gives:

$$
W_{n}^{\sigma} L_{n}^{1+\beta(1-\sigma)}=\sum_{i \in N} \tilde{W}^{\sigma-1} W_{i}^{\sigma} L_{i}^{1+(\sigma-1) \frac{\alpha \epsilon-\epsilon-1}{\alpha \epsilon}} \varphi_{i}^{\sigma-1} \vartheta_{n}^{1-\sigma} \tau_{i n}^{1-\sigma} .
$$

Equations (A.17) and (A.18) are isomorphic to (a discretized version of) equations (10) and (11), respectively, in Allen and Arkolakis (2014). ${ }^{34}$ We conclude the proof by applying Theorem 1, Remarks 2 and 3, from Allen, Arkolakis, and Li (2020). First, employing the notation from Remark 3 gives:

$$
\begin{gathered}
\Gamma-\boldsymbol{K}=\left[\begin{array}{cc}
1-\sigma & (1-\sigma) \frac{\alpha \epsilon-\epsilon-1}{\alpha \epsilon} \\
\sigma & 1+\beta(1-\sigma)
\end{array}\right], \\
\boldsymbol{B}=\left[\begin{array}{cc}
1-\sigma & \beta(\sigma-1) \\
\sigma & 1+(\sigma-1) \frac{\alpha \epsilon-\epsilon-1}{\alpha \epsilon}
\end{array}\right] .
\end{gathered}
$$

\footnotetext{
${ }^{34}$ The isomorphism holds under the following parameter restrictions (with the left-hand side representing Allen and Arkolakis (2014, AA) and the right-hand side representing our setup): (1) $\alpha_{A A}=\beta$, (2) $\beta_{A A}=\frac{\alpha \epsilon-\epsilon-1}{\alpha \epsilon}$, and (3) $\sigma_{A A}=\sigma$. Under these restrictions, given the same wage normalization and inputs, both models generate the same equilibrium labor allocations and wages, $\{\boldsymbol{L}, \boldsymbol{W}\}$.
} 
When $\frac{\alpha \epsilon-\epsilon-1}{\alpha \epsilon}+\beta \leq 0$, this yields the elasticity matrix:

$$
\mathcal{A}=\left|\boldsymbol{B}(\Gamma-\boldsymbol{K})^{-1}\right|_{\odot}=\left[\begin{array}{cc}
\frac{\frac{\alpha \epsilon-\epsilon-1}{\alpha \epsilon}-1}{\sigma \frac{\alpha \epsilon-\epsilon-1}{\alpha \epsilon}-(1+\beta(1-\sigma))} & \frac{\sigma\left(\frac{\alpha \epsilon-\epsilon-1}{\alpha \epsilon}+\beta\right)}{\sigma \frac{\alpha \epsilon-\epsilon-1}{\alpha \epsilon}-(1+\beta(1-\sigma))} \\
\frac{(\sigma-1)\left(\frac{\alpha \epsilon-\epsilon-1}{\alpha \epsilon}+\beta\right)}{\sigma \frac{\alpha \epsilon-\epsilon-1}{\alpha \epsilon}-(1+\beta(1-\sigma))} & \frac{-1-\beta}{\sigma \frac{\alpha \epsilon-\epsilon-1}{\alpha \epsilon}-(1+\beta(1-\sigma))}
\end{array}\right],
$$

where $|\cdot|_{\odot}$ denotes element-wise absolute value operator. The eigenvalues of $\mathcal{A}$ are $\lambda=$ 1 and $\lambda=\frac{1+\sigma \beta+(\sigma-1) \frac{\alpha \epsilon-\epsilon-1}{\alpha \epsilon}}{1+\beta(1-\sigma)-\sigma \frac{\alpha \epsilon-\epsilon-1}{\alpha \epsilon}}$. Thus if $\frac{1+\sigma \beta+(\sigma-1) \frac{\alpha \epsilon-\epsilon-1}{\alpha \epsilon}}{1+\beta(1-\sigma)-\sigma \frac{\alpha \epsilon-\epsilon-1}{\alpha \epsilon}} \in[-1,1], \rho(\mathcal{A})=1$. Finally, since the substituted system is a constant elasticity system, by Remark 2 of Allen, Arkolakis, and Li (2020), if $\rho(\mathcal{A})=1$, the equilibrium is unique (up to a normalization in wages).

\section{B.2.2 Uniqueness of the Inversion}

In this section, we provide the proof of Proposition 2.

Proposition 2. Given parameter values $\{\alpha, \beta, \sigma, \epsilon, \theta, v, \rho\}$, fundamentals $\{\boldsymbol{H}, \boldsymbol{E}, \boldsymbol{\tau}\}$, and observed data $\{\boldsymbol{L}, \boldsymbol{W}\}$, if $\theta<1$, there exist unique (up to a normalization) unobserved fundamentals $\{\boldsymbol{B}, \boldsymbol{K}\}$ and plant-level distributions of employment and wages $\{\boldsymbol{l}, \boldsymbol{w}\}$ that rationalize the data as an equilibrium outcome of the model.

We break the proof into three sub-claims.

Claim 3. Given parameter values $\{\alpha, \beta, \sigma, \epsilon, \theta, \nu, \rho\}$, fundamentals $\{\mathcal{E}, \boldsymbol{\tau}\}$, and observed data $\{\boldsymbol{L}, \boldsymbol{W}\}$, there exists a unique (up to a normalization) set of county-level efficiency wages $\left\{W_{i}^{z}\right\}_{i \in N}$ that is consistent with an equilibrium of the model.

Proof. Plugging equations (8) and (18) into equation (11) gives:

$$
D_{n}\left(\left\{W_{i}^{z}\right\}_{i \in N}\right):=w_{n} L_{n}-\sum_{i \in N}\left\{\left(\frac{W_{n}^{z} \tau_{i n}}{\left(\sum_{\ell \in N}\left(W_{\ell}^{z} \tau_{i \ell}\right)^{1-\sigma}\right)^{\frac{1}{1-\sigma}}}\right)^{1-\sigma} L_{i} w_{i}\right\}=0
$$

If equation (A.19) characterizes an excess demand system with the gross substitution property, the set of $W_{i}^{z}$ that solve it are unique (up to a normalization). This requires four properties: (i) $D_{n}$ is continuous, (ii) $D_{n}$ is homogenous of degree zero, (iii) $\sum_{j \in \mathscr{E}_{n}} D_{n}=0$, and (iv) $D_{n}$ exhibits gross substitution. Properties (i) and (ii) follow immediately from inspection. 
Property (iii) follows from:

$$
\sum_{n} D_{n}=\sum_{n} w_{n} L_{n}-\sum_{i \in N} \underbrace{\frac{\sum_{n \in N}\left(W_{n}^{z} \tau_{i n}\right)^{1-\sigma}}{\sum_{\ell \in N}\left(W_{\ell}^{z} \tau_{i \ell}\right)^{1-\sigma}}}_{=1} L_{i} w_{i}=0
$$

To see that Property (iv) holds, note that, for $k \neq n$ :

$$
\frac{\partial D_{n}}{\partial W_{k}^{z}}=(\sigma-1) \sum_{i \in N}\left\{\left(\frac{W_{n}^{z} \tau_{i n}}{\left(\sum_{\ell \in N}\left(W_{\ell}^{z} \tau_{i \ell}\right)^{1-\sigma}\right)^{\frac{2}{1-\sigma}}}\right)^{1-\sigma}\left(W_{k}^{z}\right)^{-\sigma} \tau_{i k}^{1-\sigma} L_{i} w_{i}\right\}>0 .
$$

Since $D_{n}$ is homogenous of degree zero, by Euler's homogenous function theorem, we have $\boldsymbol{W}^{z} \nabla D_{n}=0$. This immediately implies $\frac{\partial D_{n}}{\partial E W_{n}}<0$.

Claim 4. Given parameter values $\{\alpha, \beta, \sigma, \epsilon, \theta, v, \rho\}$, fundamentals $\{\boldsymbol{E}\}$, observed data $\{\boldsymbol{L}, \boldsymbol{W}\}$, and efficiency wages $\left\{W_{i}^{z}\right\}_{i \in N}$ that satisfy equation (A.19), if $\theta<1$, there exists a unique set of knowledge $\boldsymbol{K}$ that is consistent with equation (A.12) and that pins down the plant-level distributions of employment and wages $\{\boldsymbol{l}, \boldsymbol{w}\}$.

Proof. This proof is based on the proof technique for the main theorem in Allen, Arkolakis, and Li (2020). Plugging equation (5) into equation (A.12) for all $N$ locations gives the system of equations:

$$
K_{i}=W_{i}\left(W_{i}^{z}\right)^{-1} L_{i}^{-\beta} \sum_{j=1}^{J_{i}}\left(K_{-i}^{j}\right)^{-\theta}\left(\frac{\left(K_{-i}^{j}\right)^{j}}{\Pi_{k \leq j} K_{-i}^{k}}\right)^{\theta v} \frac{\left[\frac{w_{i j}}{W_{i}}\right]^{1-j v}}{\Pi_{k \leq j}\left[\frac{w_{i k}}{W_{i}}\right]^{-v}}\left(\frac{-v}{(v j-1)(v(j-1)-1)}\right) .
$$

Let $y_{i}:=\ln K_{i}, \kappa_{i}:=W_{i}\left(W_{i}^{z}\right)^{-1} L_{i}^{-\beta}$, and $\tilde{w}_{i j}:=\frac{w_{i j}}{W_{i}}$. Let:

$$
Q_{i j}:=\left(K_{-i}^{j}\right)^{-\theta}\left(\frac{\left(K_{-i}^{j}\right)^{j}}{\Pi_{k \leq j} K_{-i}^{k}}\right)^{\theta v} \frac{\left[\tilde{w}_{i j}\right]^{1-j v}}{\Pi_{k \leq j}\left[\tilde{w}_{i k}\right]^{-v}}\left(\frac{-v}{(v j-1)(v(j-1)-1)}\right) .
$$

By Claim 1, $\tilde{w}_{i j}$ is pinned down by $\left\{K_{-i}^{j}\right\}_{j \in \mathscr{C}_{i}}$. Denote the LHS of the equation as a function 
$g_{i}$. This gives the system:

$$
g_{i}(\boldsymbol{y})=\ln \kappa_{i}+\ln \left(\sum_{j \in \mathscr{E}_{i}} \boldsymbol{Q}_{i j}(\boldsymbol{y})\right)
$$

For brevity, we suppress dependence of $\boldsymbol{Q}_{i j}$ on $\boldsymbol{y}$ in future expressions. We have:

$$
\frac{\partial g_{i}}{\partial y_{\ell}}=\frac{\sum_{j \in \mathscr{E}_{i}} Q_{i j}\left((v j-1)\left(\theta \frac{\partial \ln K_{-i}^{j}}{\partial y_{\ell}}-\frac{\partial \ln \tilde{w}_{i j}}{\partial y_{\ell}}\right)-v\left(\theta \sum_{k \leq j} \frac{\partial \ln K_{-i}^{k}}{\partial y_{\ell}}-\sum_{k \leq j} \frac{\partial \ln \tilde{w}_{i k}}{\partial y_{\ell}}\right)\right)}{\sum_{j \in \mathscr{E}_{i}} Q_{i j}} .
$$

We can show that $\frac{\partial g_{i}}{\partial y_{\ell}} \leq 0$. First, note that the denominator is always positive, so the sign of the derivative is determined by the sign of the numerator. Define:

$$
\begin{gathered}
\mathcal{U}_{j}^{i, \ell}:=\frac{\theta \mathbf{1}_{\ell \in \mathcal{E}_{j} \backslash\{i\}}}{\left|\mathcal{E}_{j}\right|-1}-\frac{\partial \ln \tilde{w}_{i j}}{\partial y_{\ell}} \\
\mathcal{I}_{i j}:=\left(\frac{\left(\frac{\left(K_{-i}^{j}\right)^{\theta}}{\tilde{w}_{i j}}\right)^{j v-1}}{\Pi_{k \leq j}\left(\frac{\left(K_{-i}^{k}\right)^{\theta}}{\tilde{w}_{i k}}\right)^{v}}\right)\left(\frac{-v}{v(j-1)-1}\right)+\sum_{\mathcal{M}=j+1}^{J_{i}} \frac{v^{2}}{(v \mathcal{M}-1)(v(\mathcal{M}-1)-1)}\left(\frac{\left(\frac{\left(K_{-i}^{\mathcal{M}}\right)^{\theta}}{\tilde{w}_{i \mathcal{M}}}\right)^{\mathcal{M} v-1}}{\Pi_{k \leq \mathcal{M}}\left(\frac{\left(K_{-i}^{k}\right)^{\theta}}{\tilde{w}_{i k}}\right)^{v}} .\right.
\end{gathered}
$$

Note that the numerator of equation (A.22) is equal to $\sum_{j \in \mathscr{E}_{i}} \mathcal{U}_{j}^{i, \ell} \mathcal{I}_{i j}$. First, we show that $\mathcal{U}_{j}^{i, \ell} \geq 0$. Consider the case where $\ell \notin \mathcal{E}_{j} \backslash\{i\}$. It is straightforward to show that $\frac{\partial \ln \mathcal{L} \mathcal{D}_{i j}}{\partial y_{\ell}} \leq$ 0 , which implies $\frac{\partial \ln \tilde{w}_{i j}}{\partial y_{\ell}} \leq 0$. Next, consider the case where $\ell \in \mathcal{E}_{j} \backslash\{i\}$. Suppose that $\frac{\partial \ln \tilde{w}_{i j}}{\partial y_{\ell}}>\frac{\theta \mathbf{1}_{\ell \in \mathcal{E}_{j} \backslash\{i\}}}{\left|\mathcal{E}_{j}\right|-1}$. This implies, in response to small shocks, that labor demanded by plant $\{i, j\}$ decreases, but labor supplied to plant $\{i, j\}$ increases $\rightarrow \leftarrow$. Thus, $\frac{\partial \ln \tilde{w}_{i j}}{\partial y_{\ell}} \leq \frac{\theta \mathbf{1}_{\ell \in \mathcal{E}_{j} \backslash\{i\}}}{\left|\mathcal{E}_{j}\right|-1}$. Next, it is straightforward to show that $\mathcal{I}_{i j}<-w_{i j} s_{i j} \underline{\mathrm{z}}_{i j} W_{i} K_{i}^{-1} L_{i}^{-\beta}<0$ for (almost) all $j$. Combined, $\mathcal{U}_{j}^{i, \ell} \geq 0$ and $\mathcal{I}_{j}^{i, \ell} \leq 0$ implies that the numerator of equation (A.22) is less than or equal to zero, and thus $\frac{\partial g_{n}}{\partial y_{\ell}} \leq 0$ for any $n, l$.

Next, we characterize $\sum_{\ell \in N} \frac{\partial g_{n}}{\partial y_{\ell}}(\hat{\boldsymbol{y}})$. After some manipulation of equation (A.22), we get:

$$
-\theta \leq \sum_{\ell \in N} \frac{\sum_{j \in \mathscr{C}_{i}} Q_{i j}\left(\theta(v j-1)\left(\frac{\partial \ln K_{-i}^{j}}{\partial y_{\ell}}\right)-v \theta \sum_{k \leq j} \frac{\partial \ln K_{-i}^{k}}{\partial y_{\ell}}\right)}{\sum_{j \in \mathscr{C}_{i}} Q_{i j}} \leq 0 .
$$


Using the chain rule, we can re-write wage responses as $\frac{\partial \ln \tilde{w}_{i j}}{\partial y_{\ell}}=\theta \sum_{k \in \mathscr{C}_{i}} \frac{\partial \ln \tilde{w}_{i j}}{\partial \ln \bar{z}_{i k}} \frac{\mathbf{1}_{\ell \in \mathcal{E}_{k} \backslash\{i\}}}{\left|\mathcal{E}_{k}\right|-1}$. By Claim 1, $\frac{\partial \ln \tilde{w}_{i j}}{\partial \ln K_{i}}=0$. Applying again the chain rule, $\frac{\partial \ln \tilde{w}_{i j}}{\partial \ln K_{i}}=\sum_{k \in \mathscr{C}_{i}} \frac{\partial \ln \tilde{w}_{i j}}{\partial \ln \bar{z}_{i k}} \frac{\partial \ln \bar{z}_{i k}}{\partial \ln K_{i}}=$ $\sum_{k \in \mathscr{C}_{i}} \frac{\partial \ln \tilde{w}_{i j}}{\partial \ln \bar{z}_{i k}} \rightarrow \sum_{k \in \mathscr{C}_{i}} \frac{\partial \ln \tilde{w}_{i j}}{\partial \ln \bar{z}_{i k}}=0$. Altogether, it can be shown that:

$$
-\theta \leq \sum_{\ell \in N} \frac{\partial g_{n}}{\partial y_{\ell}}(\hat{\boldsymbol{y}}) \leq 0 .
$$

Finally, we move on to prove the result. By the mean value theorem, $\forall\left\{\boldsymbol{y}, \boldsymbol{y}^{\prime}\right\} \in \mathbb{R}_{++}^{2 N}, \exists \tau \in$ $[0,1]$ such that (i) $\hat{\boldsymbol{y}}=\tau \boldsymbol{y}+(1-\tau) \boldsymbol{y}^{\prime}$ and (ii) $g_{n}(\boldsymbol{y})-g_{n}\left(\boldsymbol{y}^{\prime}\right)=\nabla g_{n}(\hat{\boldsymbol{y}})\left(\boldsymbol{y}-\boldsymbol{y}^{\prime}\right)$. This implies:

$$
\begin{aligned}
\left|g_{n}(\boldsymbol{y})-g_{n}\left(\boldsymbol{y}^{\prime}\right)\right| & \leq-\sum_{\ell \in N}\left|y_{\ell}-y_{\ell}^{\prime}\right| \frac{\partial g_{n}}{\partial y_{\ell}}(\hat{\boldsymbol{y}}) \leq-\sum_{\ell \in N} \max _{\kappa \in N}\left|y_{\kappa}-y_{\kappa}^{\prime}\right| \frac{\partial g_{n}}{\partial y_{\ell}}(\hat{\boldsymbol{y}}) \\
& =-\max _{\kappa \in N}\left|y_{\kappa}-y_{\kappa}^{\prime}\right| \sum_{\ell \in N} \frac{\partial g_{n}}{\partial y_{\ell}}(\hat{\boldsymbol{y}}) \leq \theta \max _{\kappa \in N}\left|y_{\kappa}-y_{\kappa}^{\prime}\right|
\end{aligned}
$$

Recall that $\left(\mathbb{R}^{N}, d_{\infty}\right)$ is a complete metric space. Equation (A.23) shows that, if $\theta<1$, the function $g_{n}$ is a contraction mapping. Uniquess of $\boldsymbol{K}$ follows from the Banach Fixed Point Theorem. Finally, by Claim $1, \boldsymbol{K}$ pins down $\{\boldsymbol{l}, \boldsymbol{w}\}$.

Claim 5. Given parameter values $\{\alpha, \beta, \sigma, \epsilon, \theta, v, \rho\}$, fundamentals $\{\boldsymbol{H}, \boldsymbol{E}, \boldsymbol{\tau}\}$, observed data $\{\boldsymbol{L}, \boldsymbol{W}\}$, (recovered) efficiency wages $\left\{W_{i}^{z}\right\}_{i \in N}$, and (recovered) plant-level distributions of employment and wages $\{\boldsymbol{l}, \boldsymbol{w}\}$, there exists a unique (up to a normalization) set of amenity scale parameters $\boldsymbol{B}$ such that the observed data are an equilibrium of the model.

Proof. The proof is identical to the proof of Proposition 3 in Redding (2016).

\section{Estimation Appendix}

The parameter vector estimate $\hat{\Theta}$ minimizes the loss function $(\boldsymbol{m}-\boldsymbol{m}(\Theta))^{\prime} \boldsymbol{G}(\boldsymbol{m}-\boldsymbol{m}(\Theta))$, where $\boldsymbol{m}$ denotes data moments and $\boldsymbol{m}(\Theta)$ denotes model-based moments. We obtain $\boldsymbol{m}(\Theta)$ by estimating plant-level difference-in-differences regressions using a data set with "pre-" and "post-shock" observations. Given a guess of the model parameters $\Theta$, we construct this data set in two steps:

1. Pre-Shock Equilibrium and Recovery of Fundamentals: We generate a plant-level data set that corresponds to the pre-shock equilibrium of the model. To this end, we invert the equilibrium conditions of the model and use the recursive structure 
from the proof of Proposition 2. We first recover the set of county-level efficiency wages that satisfies equation (A.19) (see Claim 3 in Appendix B.2). Second, we implement the contraction mapping that recovers the set of county-level knowledge $\boldsymbol{K}(\Theta)$, described in equation (A.21) (see Claim 4). By Claim 1, $\boldsymbol{K}(\Theta)$ pins down within-county labor shares and relative wages, $\boldsymbol{l}(\Theta)$ and $\boldsymbol{w}(\Theta)$. Third, we recover the set of amenity scale parameters $\boldsymbol{B}(\boldsymbol{\Theta})$ that satisfy equation (12) (see Claim 5). By Proposition 2, the recovered county-level characteristics and within-county distributions are unique up to a normalization. ${ }^{35}$

2. Post-Shock Equilibrium. We shock the economy with 47 independent local productivity shocks that resemble the MDP openings, as described in Section 4.3. For each MDP case $c$, we use the model's recursive structure to recover wages and employment for the post-shock equilibrium, $\left\{\boldsymbol{L}_{c}^{\prime}(\Theta), \boldsymbol{W}_{c}^{\prime}(\Theta), \boldsymbol{l}_{c}^{\prime}(\Theta), \boldsymbol{w}_{c}^{\prime}(\Theta)\right\}$. First, given $\boldsymbol{K}_{c}^{\prime}(\boldsymbol{\Theta})$, we recompute plants' productivity scale parameters using equation (5). Second, we recover within-county labor shares and relative wages, $l(\Theta)$ and $\boldsymbol{w}(\Theta)$, using the recursive structure of equation (A.13) (see Claim 1 in Appendix B.2). Third, we use equations (A.14) and (A.15) to solve for the exogenous amenity wage and efficiency wage "slopes" $\left\{g_{n}\left(\left\{K_{-n}^{j}\right\}_{j \in \mathscr{C}_{n}}\right), h_{n}\left(\left\{K_{-n}^{j}\right\}_{j \in \mathscr{C}_{n}}\right)\right\}_{n \in N}$ (see Claim 2). Finally, we iterate over post-shock equilibrium county-level wages and employment, $\boldsymbol{W}_{c}^{\prime}(\boldsymbol{\Theta})$ and $\boldsymbol{L}_{c}^{\prime}(\Theta)$, until we find the values that simultaneously satisfy equations (A.17) and (A.18) for each MDP case $c$.

\section{References}

Allen, Treb, and Costas Arkolakis, 2014, Trade and the Topography of the Spatial Economy, Quarterly Journal of Economics 129, 1085-1140.

Allen, Treb, Costas Arkolakis, and Xiangliang Li, 2020, On the Equilibrium Properties of Network Models with Heterogeneous Agents, mimeo, Dartmouth College.

Ellison, Glenn, Edward Glaeser, and William Kerr, 2010, What Causes Industry Agglomeration? Evidence from Coagglomeration Patterns, American Economic Review 100, 1195-1213.

Hadlock, Charles, and Joshua Pierce, 2010, New Evidence on Measuring Financial Constraints: Moving Beyond the KZ Index, Review of Financial Studies 23, 1909-1940.

\footnotetext{
${ }^{35}$ We normalize efficiency wages and and amenity scale parameters such that their geometric mean is one.
} 
Kaplan, Steven, and Luigi Zingales, 1997, Do Investment-Cash Flow Sensitivities Provide Useful Measures of Financing Constraints? Quarterly Journal of Economics 112, 169-215.

Lind, Nelson, and Natalia Ramondo, 2021, Trade with Correlation, mimeo, Emory University.

Redding, Stephen, 2016, Goods Trade, Factor Mobility and Welfare, Journal of International Economics 101, 148-167. 